\title{
Full-Scale Impact Test and Numerical Simulation of a New-Type Resilient Rock-Shed Flexible Buffer Structure
}

\author{
Z. X. Yu, ${ }^{1,2,3}$ L. Zhao ${ }^{1},{ }^{1,4}$ L. P. Guo ${ }^{\mathbb{D}},{ }^{1}$ Y. P. Liu, ${ }^{1,4}$ C. Yang, ${ }^{1}$ and S. C. Zhao ${ }^{1}$ \\ ${ }^{1}$ School of Civil Engineering, Southwest Jiaotong University, Chengdu, China \\ ${ }^{2}$ Shock and Vibration of Engineering Material and Structure Key Laboratory of Sichuan Province, Mianyang, China \\ ${ }^{3}$ China-Japan Resilient and Sustainable Concrete Structure Research Center, Chengdu, China \\ ${ }^{4}$ Department of Civil and Environmental Engineering, The Hong Kong Polytechnic University, Hung Hom, Hong Kong
}

Correspondence should be addressed to L.Zhao; zhaolei@my.swjtu.edu.cn

Received 18 February 2019; Revised 3 April 2019; Accepted 15 April 2019; Published 2 May 2019

Academic Editor: Nicola Nisticò

Copyright (c) 2019 Z.X. Yu et al. This is an open access article distributed under the Creative Commons Attribution License, which permits unrestricted use, distribution, and reproduction in any medium, provided the original work is properly cited.

\begin{abstract}
Rock sheds have been widely used to protect against rockfall. Traditionally, a cushion layer is placed on the top of a rock shed to reduce the impact force and dissipate energy. However, heavy cushion layers lead to high dead loads and increased construction costs. This paper discusses the concept of an impact-resilient flexible buffer structure. On the basis of that concept, it also proposes a buffer structure mainly composed of springs, ring nets, spring rods, and support ropes, which can be used to replace the traditional cushion layer on a shed for rockfall protection. Full-scale impact tests were conducted to study the impact-resilient characteristic of the structure combined with numerical simulation. The dynamic responses of the buffer structure, including force, deformation, and energy dissipation, were analysed in depth. Finally, parametric numerical simulations of 33 models were conducted; the spring stiffness of these models ranged from $300 \mathrm{kN} / \mathrm{m}$ to $1500 \mathrm{kN} / \mathrm{m}$; the impact energy ranged from $100 \mathrm{~kJ}$ to $2000 \mathrm{~kJ}$. Moreover, simple approaches for estimating the impact force and braking distance of the buffer structure were proposed and verified using measured data obtained from the impact test.
\end{abstract}

\section{Introduction}

Rockfall is one of the most common natural hazards in mountainous regions with the characteristics of high frequency and unpredictability. In addition to concrete dams and flexible barriers, rock shed is a useful protection measure, and it has been widely used at tunnel entrances of highways and railways in high-risk regions. Cushion layers (Figure 1(a)), usually composed of sand or soil, are commonly placed on the top of a rock shed to reduce the impact force and dissipate energy [1-9]. However, traditional cushion layers have several disadvantages, such as heavy weight, poor buffering performance, easy accumulation, and difficult maintenance and clean up [2, 9-11]. Moreover, a thicker cushion layer is often necessary to satisfy the actual requirements, resulting in high dead loads and increased construction costs.

Many researchers have focused on optimising the cushion layer to improve the impact resistance against rockfall. Using impact tests, Kawahara and Muro [4] found that an increase in the thickness of sand cushion can effectively reduce the impact force, and this effect increases as the dry density of the cushion material decreases. Schellenberg et al. [7] designed three kinds of damping blocks consisting of geotextiles, steel wire meshes and three different types of granular fillers, sandy soil, foam glass, and gravel. They used impact tests to study the dynamic responses, such as impact force, duration, and impact deformation. Wang et al. [12] and Zarnani and Bathurst [13] also studied the buffering performance of expanded polystyrene (ESP) in civil air defence engineering and retaining wall projects. Sun et al. [14] studied the buffering performance of a rubber tire cushion using 12 impact tests; they reported that rubber tires can significantly reduce the impact force, and the buffering performance will be further enhanced when the tire is filled with sand or gravel. Hsu et al. $[2,3]$ studied the impact resistance of a composite cushion made of EPS, a steel grille, and steel wire meshes; they found 


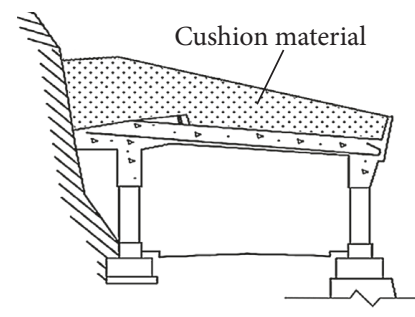

(a)

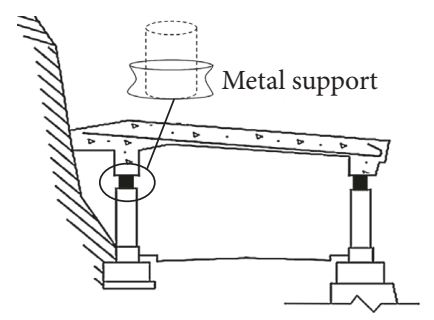

(b)

FIgURE 1: Typical traditional reinforced concrete (RC) rock shed. (a) Cushion layer. (b) Metal support.

that in comparison to sand cushion, the composite cushion reduced the maximum impact force by $50 \%$. Effeindzouro et al. [15] proposed a discrete element model of the damping block, and they reproduced the impact test based on Schellenberg's research (2006).

In practice, in addition to placing a cushion layer on the top of a rock shed, metal energy dissipators have been recently introduced and placed on the critical load paths of a rock shed to improve the impact resistance capacity (Figure 1(b)). Delhomme et al. [10, 11] and Mougin et al. [16] installed compressed metal supports on the column tops of a reinforced concrete (RC) shed to dissipate energy and reduce the impact force. Castanon-Jano et al. [17] provided an overview of the buffering performance of tensile energy dissipators used to protect against rockfall using various indicators, such as impact tests, numerical simulation, and mechanical behaviour. Because a metal energy dissipator can dissipate high energy with a small amount of material, it has a very high energy dissipation/mass ratio $(\mathrm{E} / \mathrm{M})$, which can significantly reduce the consumption of buffering materials; thus, it has been widely used in flexible rockfall barriers.

For rapid disaster relief, the so-called "flexible shed," composed of a steel structure, steel wire meshes, and energy dissipating devices, has been used in China for rockfall protection along traffic lines for many years. Unfortunately, very few previous studies have researched this topic. In recent years, Shi et al. [18] developed a new concept of a flexible rock shed, an H-beam steel arch structure acting as the supporting structure with ring nets laid on that structure. Due to the nonlinear large deformation capacity of the ring nets, the buffering performance of the flexible shed is good. The full-scale test indicated that the flexible shed could withstand approximately $250 \mathrm{~kJ}$ of the impact energy; the maximum elongation was about 2.3 meters. When comparing the flexible shed to the traditional shed, the most notable change was the introduction of the flexible buffer unit composed of ring nets. Dynamic finite element analysis of the shed [19] was also conducted to improve its design. However, the buffering capacity of the shed was limited due to the lack of energy dissipators. In practice, the flexible shed is easily damaged due to the failure of the steel elements, puncturing or cutting damage of the ring nets.

In general, inelastic deformation is beneficial to energy dissipation, but it reduces the resilience of the structure. Elastic deformation is advantageous to the resilience of the structure, but the buffering performance is limited due to poor energy dissipation.
While the studies mentioned above have improved the ability to prevent rockfall disasters, in practice, rockfall accumulation and structural damage still frequently occur. Not only flexible rock sheds (Figure 2(a)), but even traditional RC sheds (Figure 2(b)) are sometimes severely damaged by rockfalls. New approaches characterised by a short construction period, strong resilience capacity, and easy maintenance are urgently needed to solve the problems caused by rockfalls along transport routes. Flexible sheds provide a possible solution for these problems, but several typical issues still need to be addressed due to the lack of basic research. First, the buffering performance of flexible sheds needs to be improved. For example, Shi et al. [18] full-scale test model can only resist the impact energy of $250 \mathrm{~kJ}$ that is far from the protection demand of thousands of kJ energy, such as the capacity of passive flexible barriers [20-23]. Individual buffer units are needed to significantly improve the system's buffering performance rather than relying solely on the large deformation of flexible nets. Second, the existing flexible sheds are vulnerable to rockfall because the flexible nets are often laid directly on the steel arch frame. That problem may be solved by increasing the distance between the flexible nets and the steel structure. Third, most of the existing sheds adopt a steel frame with a compressive and bending capacity, which is prone to causing permanent damage or lateral deformation under the impact of rockfall. If the structural members are as parallel as possible to the impact direction of the rockfall and if they have mechanical characteristics, such as truss elements, the adverse effect can be significantly reduced. Finally, to increase the resilience of the shed, the inelastic deformation of the structure should be decreased and the elastic large deformation of the structure should be increased.

This paper discusses the concept of impact-resilient flexible buffer structure. On the basis of that concept, it then proposes an impact-resilient flexible buffer structure mainly composed of ring nets, supporting ropes, spring rods, and spring coils. In practice, the buffer structure can be installed on the top of the RC or steel structure shed to achieve the buffering and interception of rockfalls. A fullscale buffer unit was designed, and two impact tests, with an impact energy of $25 \mathrm{~kJ}$ and $50 \mathrm{~kJ}$, respectively, were conducted in succession to study the impact-resilient characteristic of the structure combined with numerical simulation. The dynamic responses of the buffer structure, including force, deformation, and energy dissipation, were 


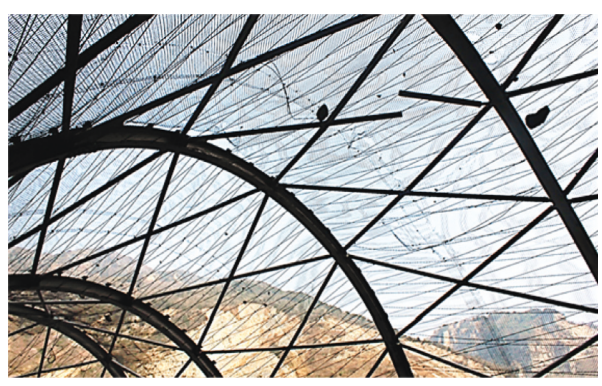

(a)

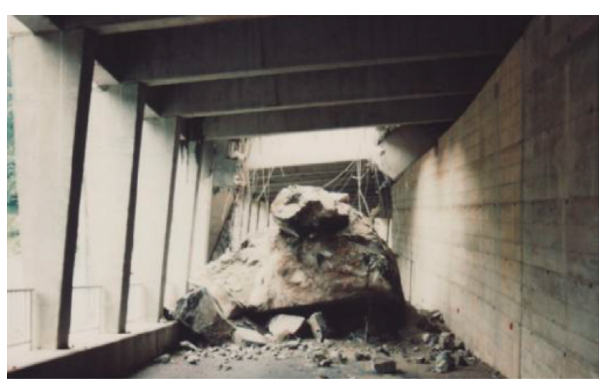

(b)

Figure 2: Failed rock shed. (a) Flexible rock shed. (b) RC rock shed [1].

analysed in depth. Finally, simple approaches for estimating the impact force and braking distance of the buffer structure were proposed using 33 parametric numerical simulations and then verified using measured data obtained from the impact test.

\section{Development of the Impact-Resilient Flexible Buffer Structure}

2.1. Concept of an Impact-Resilient Buffer Structure. Structural resilience is defined as the ability to maintain balance or stability. The focus is on efficiency, stability, and predictability, as Folke [24] detailed. McDaniels et al. [25] proposed the concept of structural resilience when an infrastructure suffers from extreme events; they distinctly noted that engineering resilience manifests in the ability to maintain acceptable functions during and after destructive events and the ability to restore all functions within a specified time.

According to Holling [26] and McDaniels et al. [25], the resilience of buffer layers/structures can be defined as shown in Figure 3. Curve (a) and curve (b) represent buffer layers/structures with poor resilience, such as sand layers placed on the top of concrete sheds, which are difficult to repair or can only be restored with incomplete functions after a long repair duration. Curve (c) represents buffer layers/structures with a specific amount of resilience, such as rubber tire cushions; these kinds of buffer layers/ structures can be repaired to restore the original function, but the repair duration is long. Curve (d) represents buffer layers/structures with good resilience; they return to the original state after impact, and the repair duration is short. Curve (d) is the goal of the buffer structure proposed in this paper.

The performance curves of buffer layers/structures can, generally, be summarised into three categories as follows: linear elastic, nonlinear elastic, and nonlinear plastic (Figure 4). The linear elastic buffer layers/structures, shown as curve (a) in Figure 4, are characterised by little residual deformation, which benefits the excellent self-recovery performance, as seen in curve (d) in Figure 3. However, the energy dissipation capacity is very low. Therefore, this kind of buffer layer/structure is rarely adopted because the impact force cannot be effectively reduced due to the small braking distance and because the impact energy cannot be effectively dissipated. Nonlinear plastic buffer layers/ structures, shown as curve (d) in Figure 4, have been widely used in practice; they are characterised by large plastic deformation, which significantly benefits energy dissipation. However, the residual deformation of this kind of buffer layer/structure is large, resulting in rockfall accumulation, pore residual impact resistance capacity, and maintenance difficulties. Therefore, their self-recovery performance is poor, as shown in curve (a) in Figure 3. Linear elastic buffer layers/structures, shown as curve (b) and curve (c) in Figure 4, are characterised by large elastic deformation. In comparison to curve (d) in Figure 4, the energy dissipation capacity varies greatly, due to differences in the recovery path. The advantages of this kind of buffer layer/ structure mainly lie in small residual deformation and considerable braking distance, resulting in a good selfrecovery performance and a low impact load. A comprehensive comparison of the different types of buffer layers/ structures shows that the nonlinear elastic buffer layer/ structure is the best, and it is the theoretical basis for the impact-resilient flexible buffer structure proposed in this paper.

From the energy balance control equation (equation (1)), it is known that the internal energy of a buffer structure is one of the conversion modes of the impact energy of rockfall. It can be dissipated and/or released after being stored. The dissipation of internal energy mainly depends on large unrecoverable plastic deformation; this naturally contradicts the desirable self-recovery performance of a buffer structure. However, if the impact energy is temporarily converted to elastic potential energy and stored in the structure and then released by repeated rebound, it may be dissipated by structural damping, air damping, etc. This energy dissipation strategy can effectively reduce the impact load on the structure; however, it can also dissipate the impact energy. Therefore, this strategy is chosen for the impact-resilient flexible buffer structure proposed in this paper. However, if the elastic potential energy required to be stored in structural components is too large, it may result in the failure of the buffer structure. Therefore, it is necessary to introduce additional elastic energy storage components, which can repeatedly store and release internal energy, into the buffer structure. From the conversion between the work and the energy, as expressed in equation (2), it is known that increasing the braking distance results by introducing the 


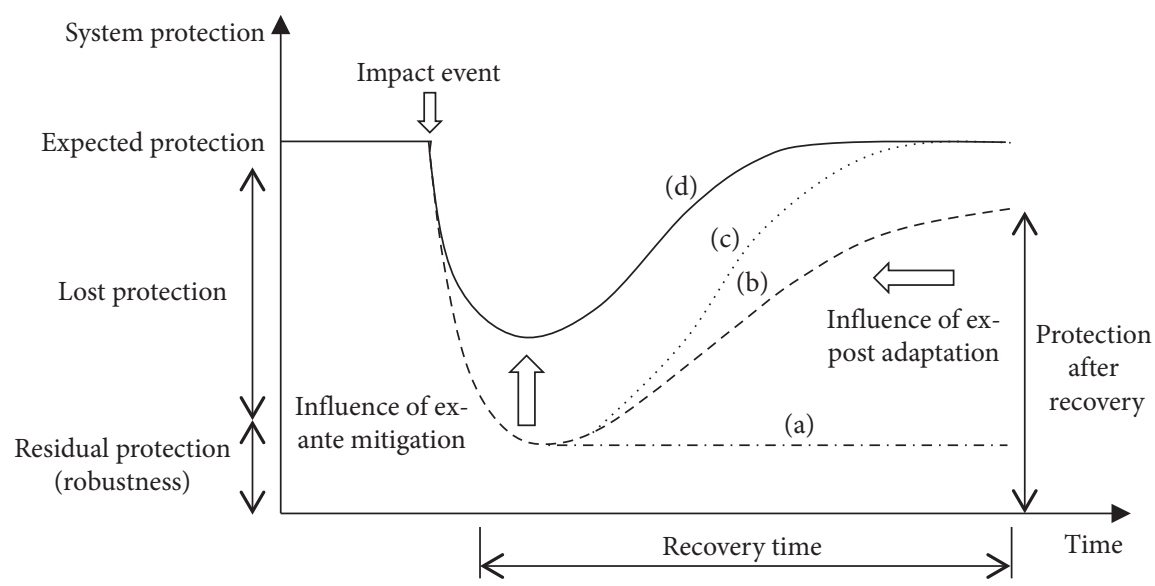

Figure 3: The resilience of buffer structures.

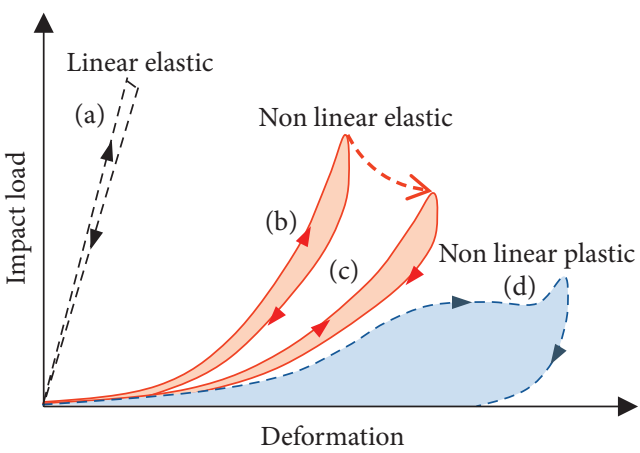

FIgURE 4: Typical performance curves of buffer layers/structures.

elastic energy storage components can effectively reduce the impact force, which reduces the possibility of structural failure and unrecoverable deformation.

$$
\begin{aligned}
& E_{\text {total }}=E_{\text {internal }}+E_{\text {damping }}, \\
& E_{\text {total }}=\int F(s) d s,
\end{aligned}
$$

where $E_{\text {total }}$ is the total impact energy of the rockfall, $E_{\text {internal }}$ is the internal energy of the buffer structure, $E_{\text {damping }}$ is the energy dissipated by damping, and $F$ is the impact force and $s$ is the braking distance.

Moreover, as mentioned above, the conceptual model of an impact-resilient buffer structure can be designed (Figure 5).

2.2. Proposal for the Impact-Resilient Buffer Structure. Recently, some researchers have successively introduced spring buffers to achieve self-recovery capabilities. Zhang et al. [27] developed and introduced a spring buffer for flexible rockfall protection systems; the spring buffer can provide some braking distance with controlled recovery. Lv [28] also developed and introduced a type of spring buffer to the so-called spring lattice debris flow dam to intercept debris flows using the elastic energy storage capacity of springs to convert the impact energy to elastic potential

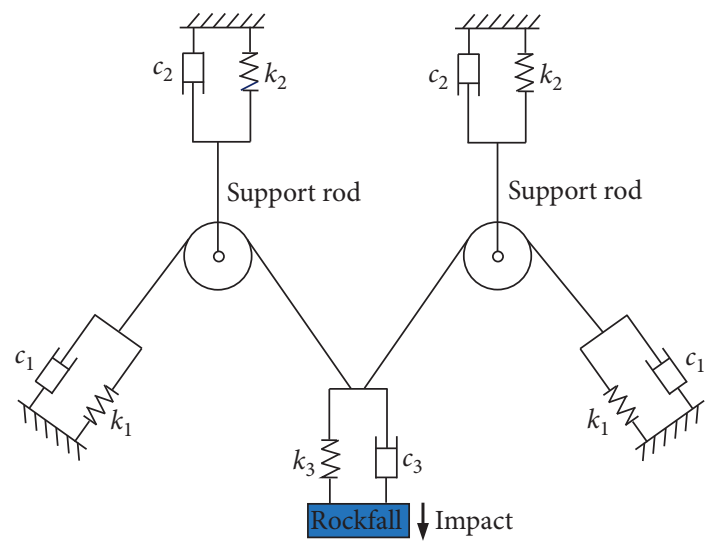

FIgURE 5: Conceptual model of an impact-resilient buffer structure.

energy; however, the impact force was reduced slightly. For these types of components or structures, the performance curves are close to the linear elastic state (curve (a) in Figure 4).

To obtain the expected rockfall impact resistance and acceptable residual deformation, the design of an impactresilient structure should focus on reducing the probabilities of failure, reducing the consequences of failure and reducing the repair duration. The fundamental solution is to enhance the structural robustness and mechanical properties during the elastic stage. Structural robustness is, generally, improved by adding the redundancies of the components. The expected elastic working properties (curve (b) and curve (c) in Figure 4) should be improved by enhancing the buffer deformation and extending the braking time of the nonlinear elastic working mechanism.

Thus, to achieve resilience, the new buffer structure requires a robust elastic working performance for two reasons. First, the individual components must provide a robust, nonlinear elastic potential energy to store the impact energy. Second, the elastic potential energy must be released to remove the fallen blocks from the interception zones, which is for self-cleaning. Moreover, to adequately improve the structural flexibility, the action of structural damping must be involved in energy dissipation. 
Previous studies $[3,4,6]$ have shown that most of the braking times of the cushion layers are less than $100 \mathrm{~ms}$, and most of the corresponding braking distances are less than $0.85 \mathrm{~m}$; the orders-of-magnitude difference is better for both in comparison to a passive flexible barrier [21-23]. Although the buffer performance of a cushion layer will improve as the thickness of the layer increases, the weight of the cushion layer will also increase and adversely affect the working performance of the rock shed below. Considering the outstanding buffer performance of a flexible rockfall barrier [21-23, 29, 30], it might be a good idea to combine a composite rock shed, an independent buffer structure based on a flexible barrier system with the main structure of a traditional RC rock shed (Figure 6(a)), and a steel rock shed (Figure 6(b)). Furthermore, the independent buffer structure primarily consists of an interception structure, a support structure, and a buffer unit. Proper connections should also be adopted to ensure the proper transmission of force and the conformability of deformation. It is important to note that although the independent buffer structure improves the buffer performance of the composite shed, increasing the braking distance $s$ may result in direct impact on the main structure at worst. Therefore, the distance between the interception structure and the main structure $h$ should be designed by comprehensively considering the braking distance $s$ and the impact force $F$ (equation (2)).

The interception structure bears the direct impact of the rock and transmits the stresses to the support ropes, the support columns, and the main structure. Although a cable net and a ring net have been widely used as the interception structure in flexible rockfall barriers for decades, the ring net has better adaptability on the transmission of impact force than the cable net. Due to its self-adaptive mechanism, a ring net can effectively reduce the material damage caused by local impact. Therefore, it is preferred for the interception structure of the buffer structure proposed in this paper.

The working mechanism of the buffer element has a significant influence on the impact deformation of the buffer structure. Although the energy dissipators that are widely used in a flexible rockfall barrier $[17,31]$ can dissipate energy effectively, a large residual deformation may result from plastic deformation, and these barriers often need to be replaced after a rockfall impact. Direct use of energy dissipators will not be conducive to the maintenance of the buffer structure. Therefore, in the model proposed in this paper, coil springs were used as the buffer unit, and they were connected to the key components, such as the support ropes and support columns, to increase the performance of the buffer structure.

The main function of the support structure is to maintain the interception structures. As mentioned above, the braking distance between the interception structure and the main structure should also be large enough to avoid direct impact on the main structure. In the model proposed in this paper, a spring rod (Figure 7), composed of a coil spring and two steel tubes with different diameters, was developed as the support structure. The smaller diameter tube is inserted into the larger diameter tube at the initial state, and the two tubes both pass through the spring. Under pressure, the distance between the baffles on the tubes will decrease, resulting in the compression of the spring and the storing of elastic potential energy. The braking distance can be adjusted by changing the length of the spring rod, and the buffer performance can be adjusted by changing the stiffness and length of the spring. To improve the robustness of the support structure, a square pyramid, consisting of four spring rods, is suggested. Both ends of the tubes are hinge joints to ensure that the tubes are subjected to axial pressure.

Four square pyramids form a separate interception space. After adding support ropes and ring nets, the integrated buffer structure (Figure 8) was constructed. Thus, the support ropes are guided on the top joints and anchored to the rock shed or foundations by springs; the ring nets are connected to the support ropes by shackles, further improving the buffering performance of the structure.

Additionally, because energy dissipators are not added in the buffer structure and the springs can store energy but not dissipate it, the rockfall will certainly rebound when the elastic potential energy that is stored in the springs is released. Therefore, if the interception structures are installed on the nonhorizontal plane, the rock will rebound out of the protected area, achieving the so-called self-cleaning feature.

\subsection{Experimental Model. To investigate the buffering per-} formance of the proposed, new impact-resilient buffer structure, a full-scale test model was designed, and two impact tests, with the rating energy of $25 \mathrm{~kJ}$ and $50 \mathrm{~kJ}$, respectively, were conducted in succession. The effective interception size and maximum allowable braking distance were $2.0 \mathrm{~m} \times 3.0 \mathrm{~m}$ and $2.0 \mathrm{~m}$, respectively, as shown in Figure 9. It is important to note that the anchor ropes anchored at the foundations and attached to the middle of support ropes were not configured in practice; they were only added to the test model to consider the lateral restraint between the buffer structures. The specifications and properties of the main components are shown in Table 1; R7/ $3 / 300$ means that each ring with a diameter of $300 \mathrm{~mm}$ was formed using seven windings of $3 \mathrm{~mm}$ diameter steel wires.

The impact tests were conducted at the National Engineering Laboratory for Prevention and Control of Geological Disasters in Land Transportation of Southwest Jiaotong University (Sichuan, China). The experimental system mainly consisted of an impact testbed, a hanging tower, blocks, a high-speed image acquisition and analysis system, load cells, and a data acquisition instrument. A polyhedral RC block $(0.6 \mathrm{~m}$ and $340 \mathrm{~kg})$ was adopted according to ETAG 027 specifications [32]. During the tests, the hanging tower lifted the block to the presupposed heights of $9.5 \mathrm{~m}$ and $17.0 \mathrm{~m}$, aimed at the central point of the net, and then freely released the block. The impact parameters of the block are shown in Table 2 .

The layout of the measuring points and the partial test instruments are shown in Figures 10(a) and 10(b), respectively. Three high-speed cameras, with a frequency of $1000 \mathrm{fps}$, were used to record the impact process from the front, axonometric, and side views, denoted as C1, C2, and $\mathrm{C} 3$, respectively. Furthermore, the tensile force versus time 


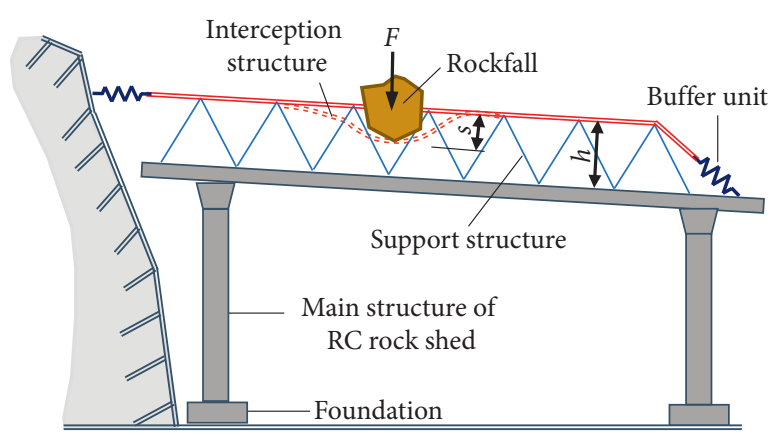

(a)

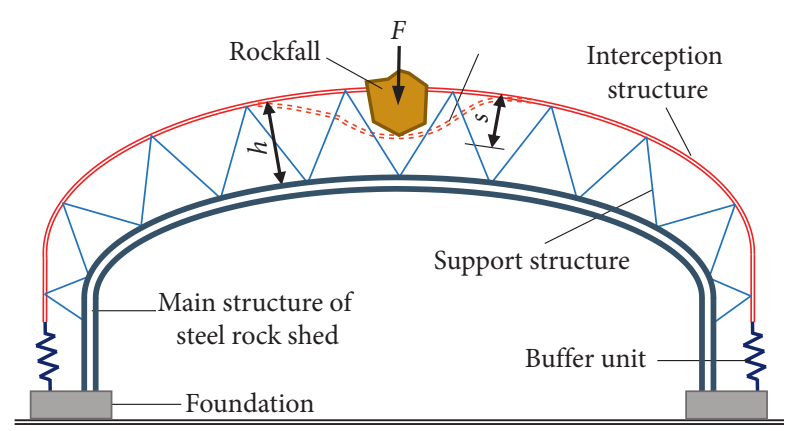

(b)

FIGURE 6: Composite rock sheds. (a) Buffer structure mounted on an RC rock shed. (b) Buffer structure mounted on a steel rock shed.

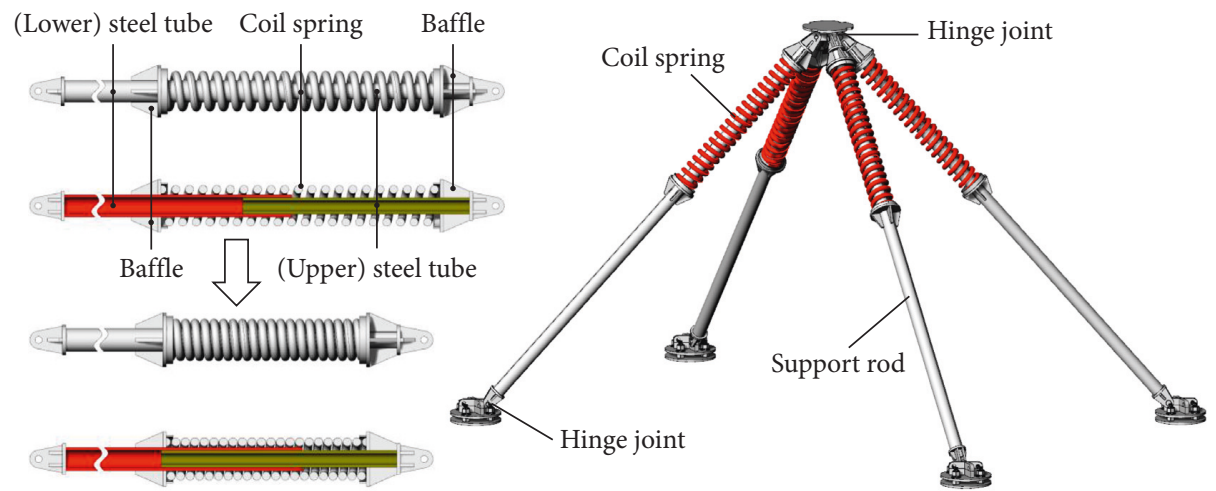

FIgURE 7: Spring rods.

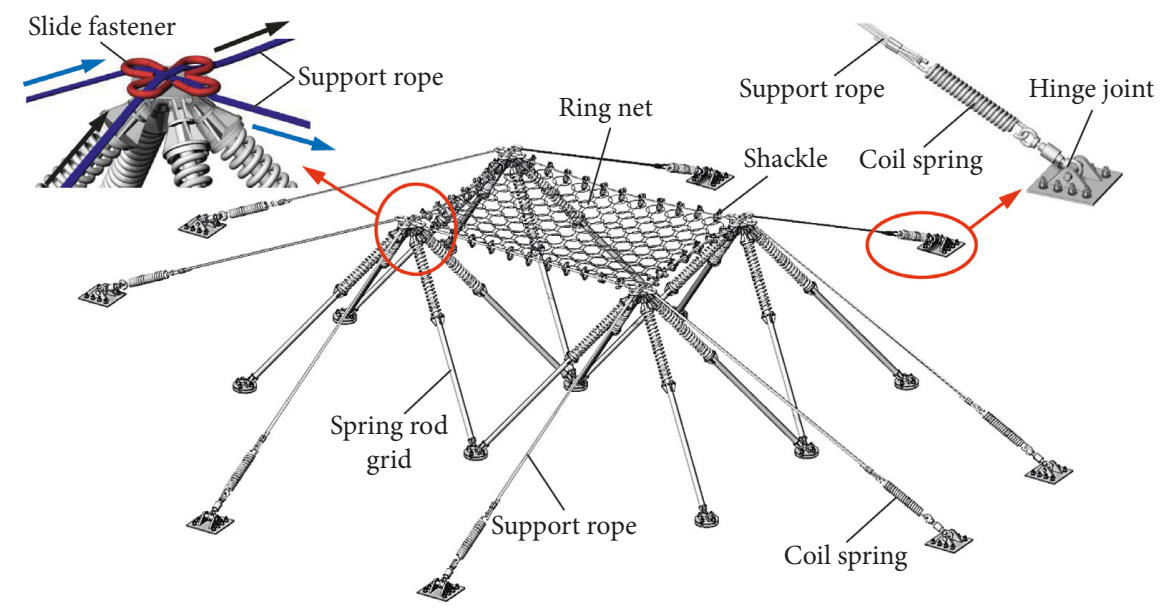

FIGURE 8: Integrated buffer structure.

curve for each of the support ropes was obtained by the load cells, with a sampling frequency of $1 \mathrm{kHz}$, which were preset on the ropes, denoted as T1-T6. The strain gauges were also preset on the spring rod in the axial direction to measure the axial pressure, denoted as S1-S6.

2.4. Numerical Model. LS-DYNA commercial software was used to further study the impact-resilient characteristic of the buffer structure. For the numerical model of the main components, except for the spring rod, please refer to papers about flexible rockfall barrier by Zhao et al. [33]; Xu et al. [34]; Qi et al. [35]; and Yu et al. [23, 36]. Furthermore, some important information about the model is detailed below.

A beam element and piecewise linear plastic material were employed to simulate the steel wire rings. A seatbelt element was used to simulate the slipping of the support rope along the top of the spring rod. An automatic beam-tosurface contact algorithm was used to simulate the contact between the block and the ring net. For modelling the actual 


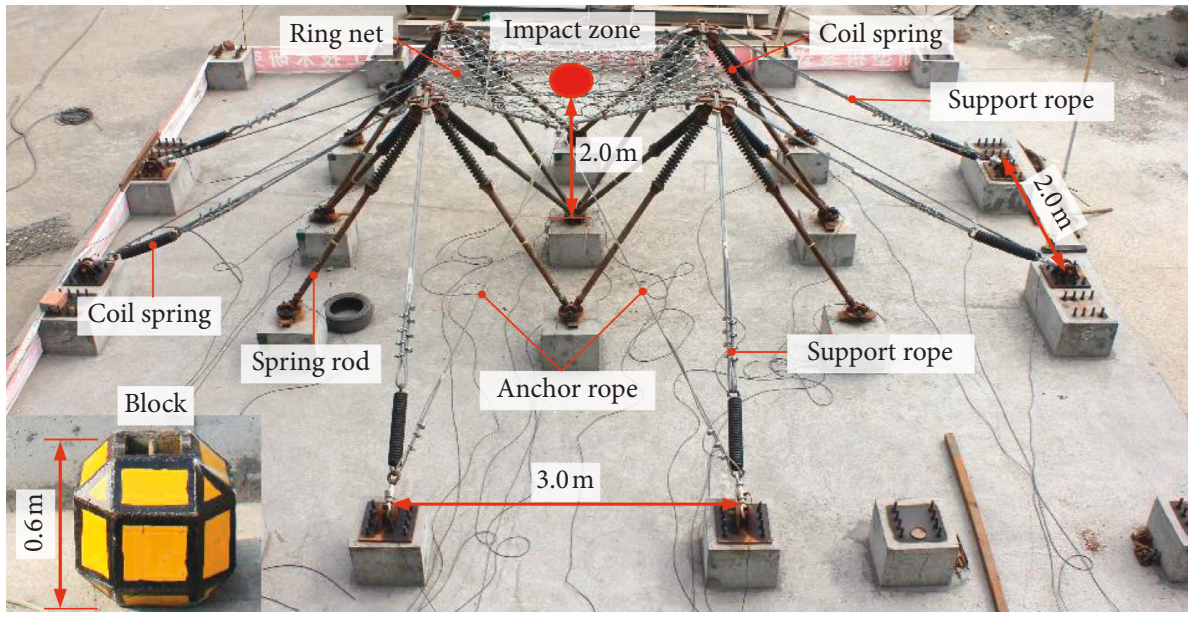

Figure 9: Test model of the buffer structure.

TABLE 1: Specifications and properties of the main components.

\begin{tabular}{lccc}
\hline Component & Specification & Material & $\begin{array}{c}\text { Yield load } \\
(\mathrm{kN})\end{array}$ \\
\hline Ring net & $\mathrm{R} 7 / 3 / 300$ & - & - \\
Support ropes & $2 \Phi 18$ & $\begin{array}{c}6 \times 19 \mathrm{~s}+\mathrm{IWR} \\
\text { (steel core) }\end{array}$ & 378 \\
Anchor ropes & $1 \Phi 16$ & $\begin{array}{c}\text { 6x19s + IWR } \\
\text { (steel core) }\end{array}$ & 150 \\
Spring rods (upper) & $\Phi 48 \times 9$ & Q235B & 206 \\
Spring rods (lower) & $\Phi 68 \times 8.5$ & $\mathrm{Q} 235 \mathrm{~B}$ & 373 \\
Coil springs & $309 \mathrm{kN} / \mathrm{m}$ & - & - \\
\hline
\end{tabular}

TABLE 2: Impact parameters of the block.

\begin{tabular}{lccc}
\hline Impact energy $(\mathrm{kJ})$ & $\begin{array}{c}\text { Mass } \\
(\mathrm{kg})\end{array}$ & $\begin{array}{c}\text { Lifted height } \\
(\mathrm{m})\end{array}$ & $\begin{array}{c}\text { Impact speed } \\
(\mathrm{m} / \mathrm{s})\end{array}$ \\
\hline 25 & 340 & 9.5 & 12.13 \\
50 & 340 & 17.5 & 17.15 \\
\hline
\end{tabular}

discrete condition of the steel wire rings, an automatic general contact algorithm was used to simulate the connection between the steel wire rings and the support ropes and the connection between each of the steel wire rings. The Coulomb friction model was employed; the dynamic friction coefficient was assumed to be 0.1 , and the static friction coefficient was 0.15 .

The spring rod was simulated by combining the translational joint with the compression spring element $[37,38]$, as shown in Figure 11. The translational joint, which consists of two coincident node pairs $\left(i_{1}, i_{2}\right)$ and $\left(j_{1}, j_{2}\right)$ and which was constrained using the penalty method, was used to link the upper and the lower steel tubes. A compression spring element was used to model the spring, which provided the compression stiffness of the translational joint. Aside from translation along the axis, the steel tubes were constrained together.

Based on the information presented above, a mechanical model of the buffer structure was built, as shown in Figure 12. Essentially, the buffer structure is a tension structure in which the flexible ring nets are continuously in tension and the support columns are discretely in compression. The good buffering performance of the structure primarily arises from the self-adaptive and rapidly changing tensile stiffness. During the impact process, the impact force $F$ is loaded onto the ring net directly, resulting in an impact displacement $d$. Then, $F$ is transmitted to the support ropes by shackles, inducing the sliding of the support ropes along the end of the spring rods. Meanwhile, the spring rods are pressed, and the springs that are linked to the support ropes are pulled. Because the spring is characterised by returning to its initial shape, the elastic potential energy stored in the springs will be released when the block reaches the lowest position, resulting in the rebound of the block.

As a flexible multibody system, the damping of the buffer structure primarily comes from mass damping. Before contact occurs between the block and the interception structure, the block is nearly a rigid body without damping. The damping of the system mainly comes from the buffer structure. After the impact occurs, the block will be part of the buffer structure, and the damping of the system will increase significantly. Thus, the damping of the system is variable. Therefore, a time-varying mass weighted damping factor $\left(D_{s}\right)$ was defined, as shown in Figure 13 [37]. When $t=0$, the block starts to fall freely, and it impacts the interception structure at $t_{1}$. After a full impact-rebound process, the block rebounds away from the interception structure at $t_{2}$. After rebounding to the highest point, the block will fall freely again, and reimpact the interception structure at $t_{3}$ once more. The buffer structure will also rebound and swing in the stage of $t_{2}-t_{3}$. $D_{\mathrm{s}}$ of the buffer structure was assumed to be a constant of 0.03 , which is a conventional value for steel structures. In the stage of contact, such as $t_{1}-t_{2}, D_{\mathrm{s}}$ of the block was assumed to be a constant of 1.0 in the simulation based on the results of the back analysis and adjustments made according to the test results. In the stage of detachment, such as $t_{2}-t_{3}, D_{\mathrm{s}}$ of the block was assumed to be 0 because it was nearly a rigid body without damping, as described above. In fact, the impactrebound process will repeat until the impact energy is 


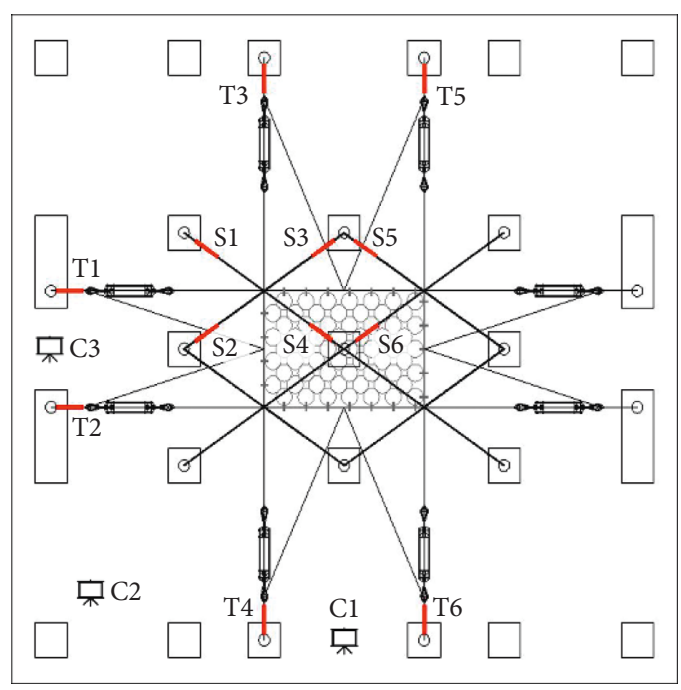

(a)

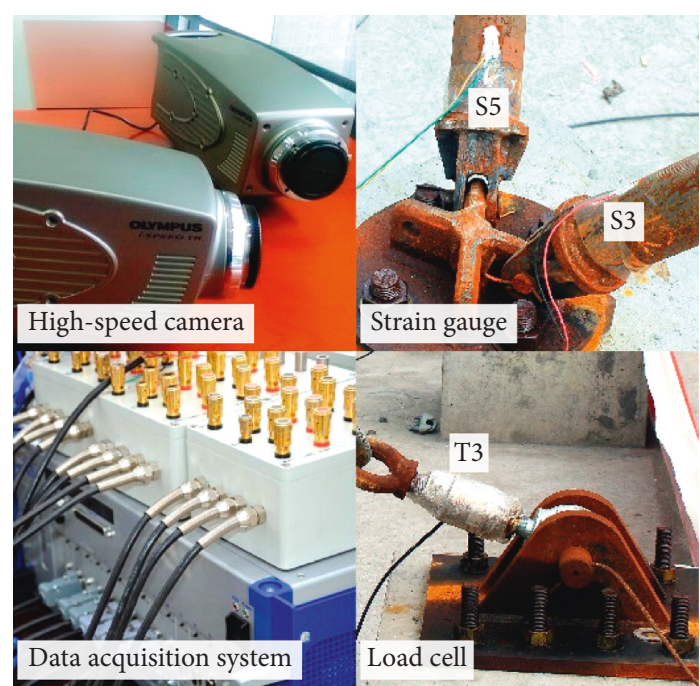

(b)

FIgURE 10: Measured points and test instruments. (a) Layout of all the measured points. (b) Partial test instruments.

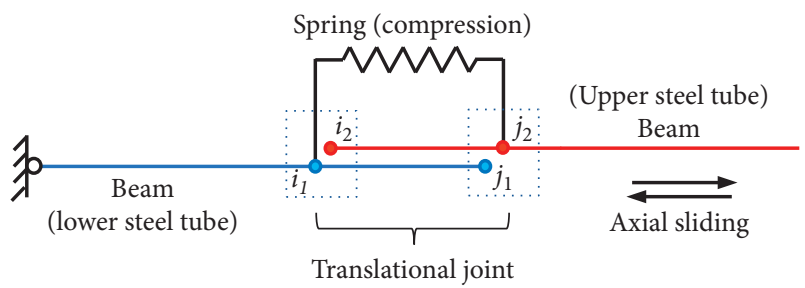

Figure 11: Spring-piston element.

dissipated completely or the block is rebounded out of the protected area of the buffer structure. The duration of each impact or rebound process can be obtained from the trial simulations and the corrections. To reduce the computation cost, the block with an initial velocity was positioned near the interception structure, instead of falling freely from the presupposed height. Because the impact force in the first stage is undoubtedly the largest in the entire impact process, the subsequent impact processes were neglected in the simulation.

\section{Mechanical Behaviours}

Both blocks in the impact tests, with energies of $25 \mathrm{~kJ}$ and $50 \mathrm{~kJ}$, respectively, were successfully intercepted; no significant damage was observed for all the components. The continuous impact of higher energy without any need for repair demonstrates the resilience of the buffer structure. In view of the similar characteristics of the impact process of the two tests, the impact test with the larger impact energy was chosen for analysis in this paper. The block experienced three impact-rebound reciprocating movements before stopping. In this paper, only the impact responses of the first impact-rebound process are analysed.

3.1. Overall Response. Several typical moments in the impact process were extracted from high-speed video and numerical simulation (FE-model A, for short), as shown in the left and middle images in Figure 14, respectively. The displacementtime curves of the block obtained from the motion analysis and the numerical simulation, respectively, are shown on the right side of Figure 14.

The impact process can be divided into three stages, as follows:

Stage I: The duration of this stage was approximately 0.07 seconds. The ring net was converted from the initial equilibrium state (Figure 14(a)) into a tight state (Figure 14(b)). The net had a V-shaped deformation. Due to the initial flexibility, the impact load was small in this stage. The spring rods were not compressed, and the springs connected to the support ropes were not stretched.

Stage II: The duration in this stage was approximately 0.06 seconds. The internal forces of the support ropes that were transferred from the ring net increased gradually until the spring rods were compressed and the springs connected to support ropes were stretched (Figure 14(c)). The ring nets had a V-shaped deformation. At the end of this stage, the deflection of the buffer structure was fully developed. The impact energy was converted to elastic potential energy, which was mainly stored in the springs.

Stage III: The duration in this stage was approximately 0.2 seconds. The block rebounded with the release of the elastic potential energy stored in the buffer structure (Figure 14(d)), and the V-shaped deformation of the ring nets disappeared.

A comparison of the principal characteristics of the impact process between the test and the numerical simulation is shown in Table 3. As seen, the simulated results were in good agreement with the test results, and the accuracy of the numerical model was verified. 


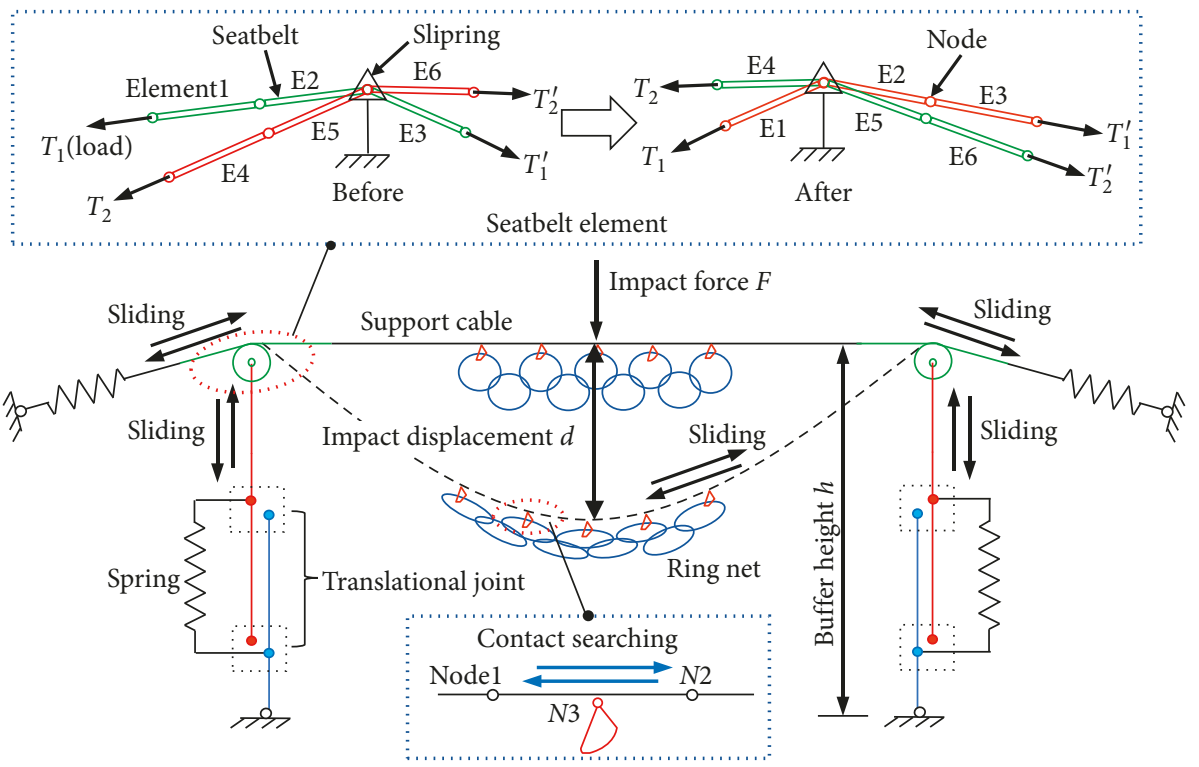

FIGURE 12: System dynamics model.

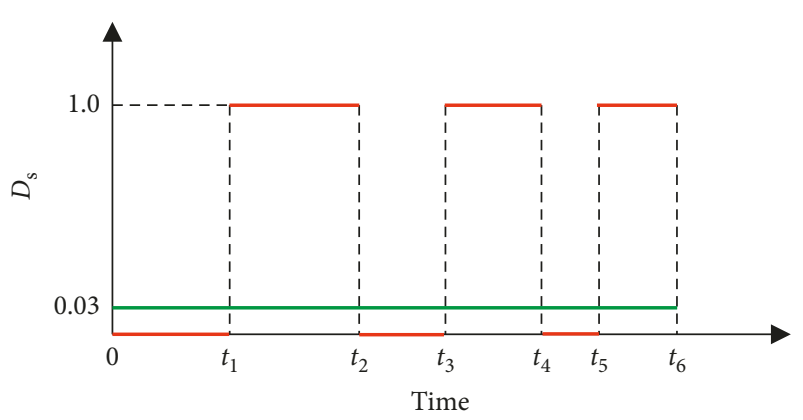

- Block

- Buffer structure

Figure 13: Time-varying mass weighted damping factor.

It is important to note that, in practice, although the installation error exists objectively, the direction of the impact is also random, and the bounciness loaded on the block is not on an ideal vertical direction. Thus, an oblique throw will occur in the first rebound process, and it will intensify gradually in the follow-up impact-rebound process until the block rebounds out of the protected area. Moreover, if the buffer structure is installed at a slant, the block may rebound out of the protected area during the first rebound process. Thus, the buffer structure has a self-cleaning feature.

3.2. Impact-Resilient Characteristic. In this section, the impact-resilient characteristic of the proposed flexible buffer structure was analysed based on the impact response of the main components and their energy dissipation characteristics.

3.2.1. Ring Nets. As described in the section about the impact process, a short $\mathrm{V}$-shaped deformation of ring nets disappeared when the block rebounded and detached from the ring nets. The test result (Figure 15(a)) shows that the deflections of the ring nets were almost the same before and after the impact $(0.53 \mathrm{~m}$ and $0.60 \mathrm{~m}$, respectively). The numerical simulation result (Figure 15(b)) also shows that the rings in the punching area were almost recovered to their original circular shapes after impact. These results indicate that, to a certain extent, the buffer structure demonstrated impact resilience.

3.2.2. Support Ropes. Figure 16 shows the time-history curves of the tensile force of the support ropes and the rope locations (see Figure 10(a)). All the peaks of the tensile forces were approximately $25 \mathrm{kN}$; thus, they were much smaller than the breaking force of the ropes (Table 1). Consequently, the support ropes were in the elastic state; they recovered to the initial state after impact, indicating that the support ropes of the buffer structure were impactresilient.

Moreover, the tensile forces of $\mathrm{T} 1$ and $\mathrm{T} 2$, which were arranged along the long direction, were slightly larger than that of T3-T6, which were arranged in the short direction. Most of the peaks were generated at $0.13 \mathrm{~s}$, which was the end of stage II. The tensile forces returned to $0 \mathrm{~s}$ after $0.25 \mathrm{~s}$. With swinging of the buffer structure, the tensile forces fluctuated slightly and gradually stabilised. The simulation results were similar to the test results, which also demonstrates the accuracy of the numerical model.

3.2.3. Spring Rods. Except for the spring rods located at the outside corner of the square pyramids, such as the measured point $S 1$ and other rods in similar positions, the rest of the rods were subjected to direct pressure, and adding spring rods may significantly reduce the axial force. The timehistory curves of the axial force of the spring rods are shown in Figure 17; the locations of measured points are 

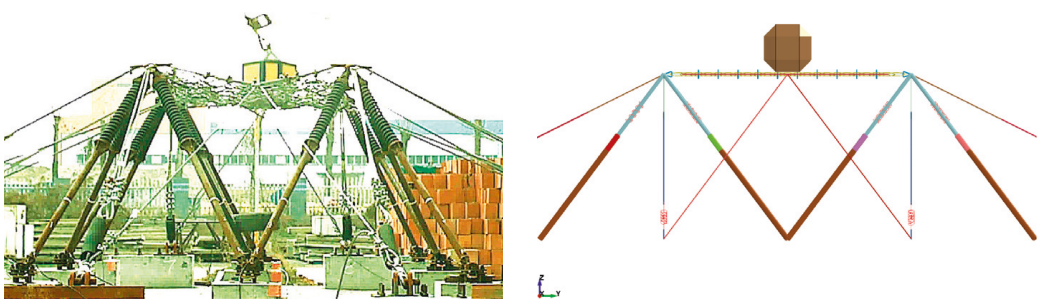

z.
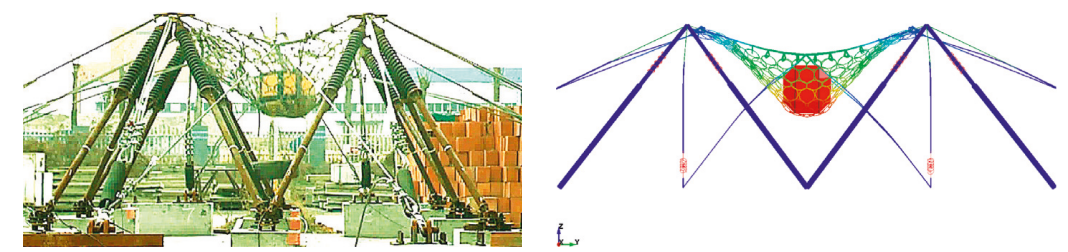

z.
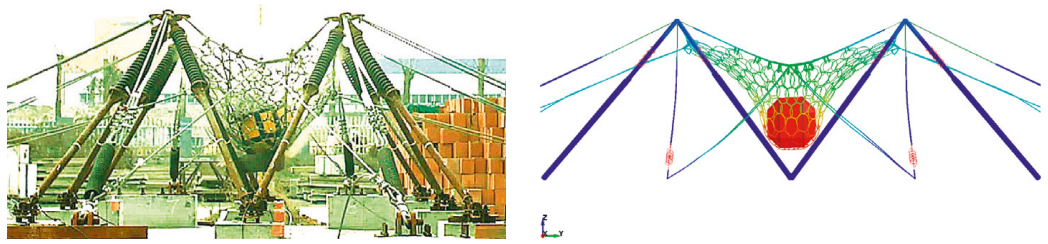

kar

(b)

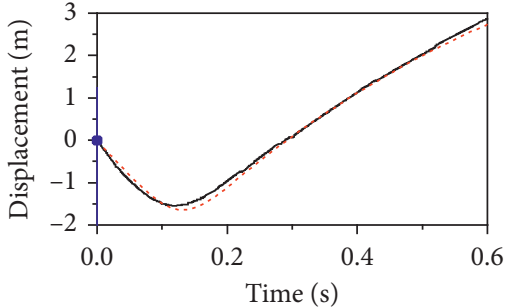

_ Test-model A

..... FE-model A

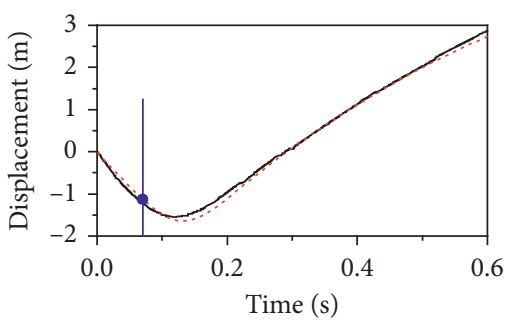

— Test-model A

...... FE-model A

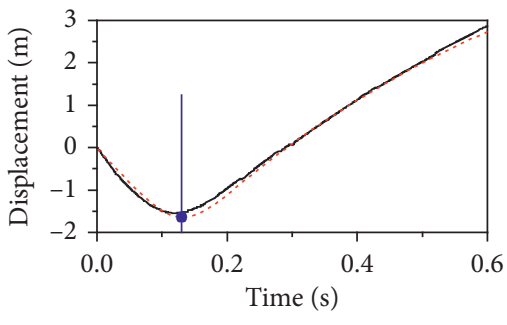

- Test-model A FE-model A

(c)
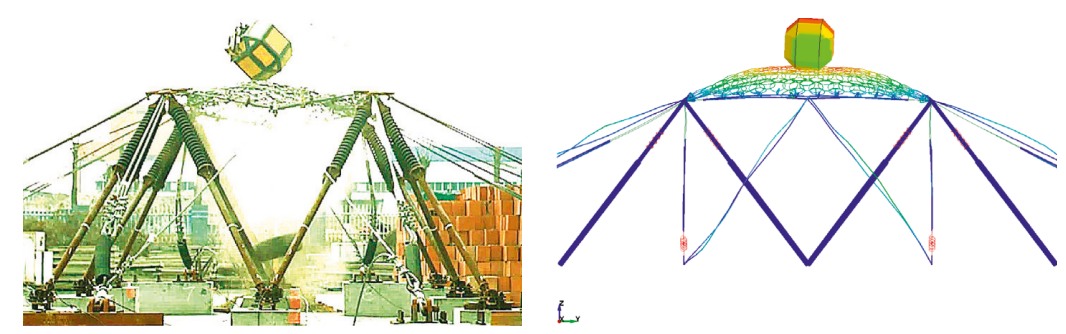

L.

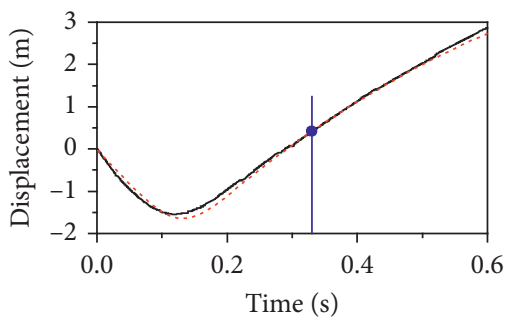

$\begin{array}{ll} & \text { Test-model A } \\ \ldots . . . & \text { FE-model A }\end{array}$

(d)

Figure 14: Deformations at several typical moments. (a) The block contacts the ring nets $(t=0 \mathrm{~s})$. (b) Compression of the spring rods $(t=0.07 \mathrm{~s})$. (c) Position of maximum impact displacement $(t=0.13 \mathrm{~s})$. (d) Block rebounds out of the ring nets $(t=0.33 \mathrm{~s})$.

shown in Figure 10. Because the spring-piston elements used in the FE-model A can only be compressed, the force of the measured point S1 was 0 (Figure 17(a)). However, in the test, due to the objective reality of friction, weak tensile force was recorded in the spring rod. The maximum axial force (Figure 17(d)) of the rods was only about $53.0 \mathrm{kN}$, which is much weaker than the yield force of the lower tube (Table 1).
Thus, the spring rods of the buffer structure were in the elastic state and recovered to the initial state after impact without any plastic deformation, indicating that they are impact-resilient.

In comparison to the model without spring rods (model B), the model with spring rods (model A) has three advantages: maximum axial force, impact duration, and 
TABLE 3: Comparison of test results and the numerical simulation results.

\begin{tabular}{lccc}
\hline Physical quantities & Test & Numerical simulation & Deviation $(\%)$ \\
\hline Maximum impact force $(\mathrm{kN})$ & 107.8 & 118.5 & 9.9 \\
Maximum elongation $(\mathrm{m})$ & 1.55 & 1.65 & 6.5 \\
Rebound height of the block $(\mathrm{m})$ & 4.04 & 4.62 & 14.4 \\
Impact duration $(\mathrm{s})$ & 0.32 & 0.33 & 3.1 \\
\hline
\end{tabular}
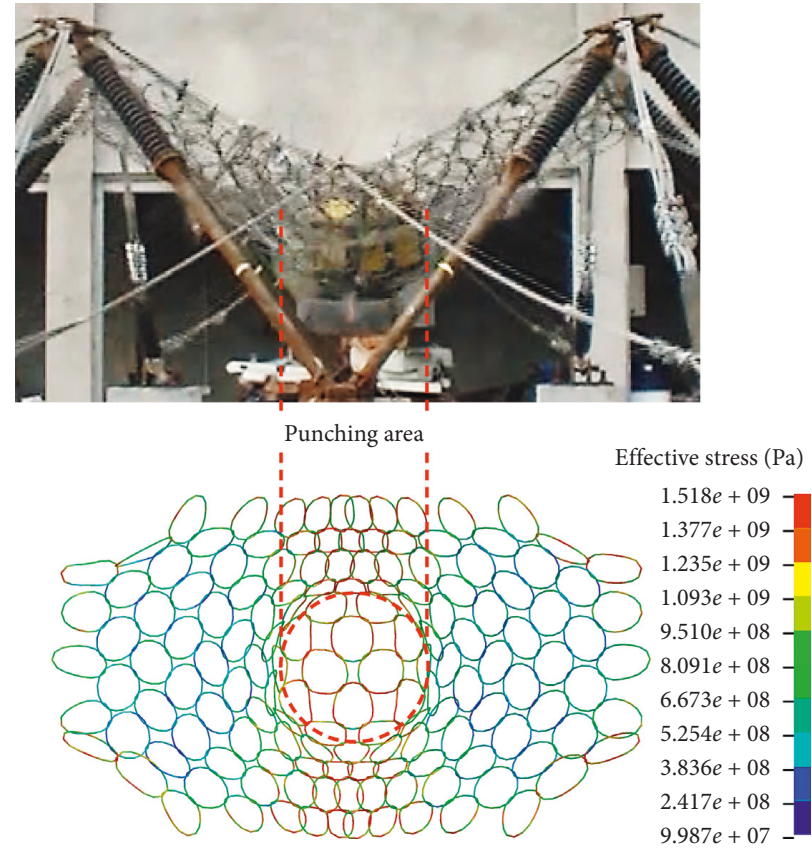

(a)
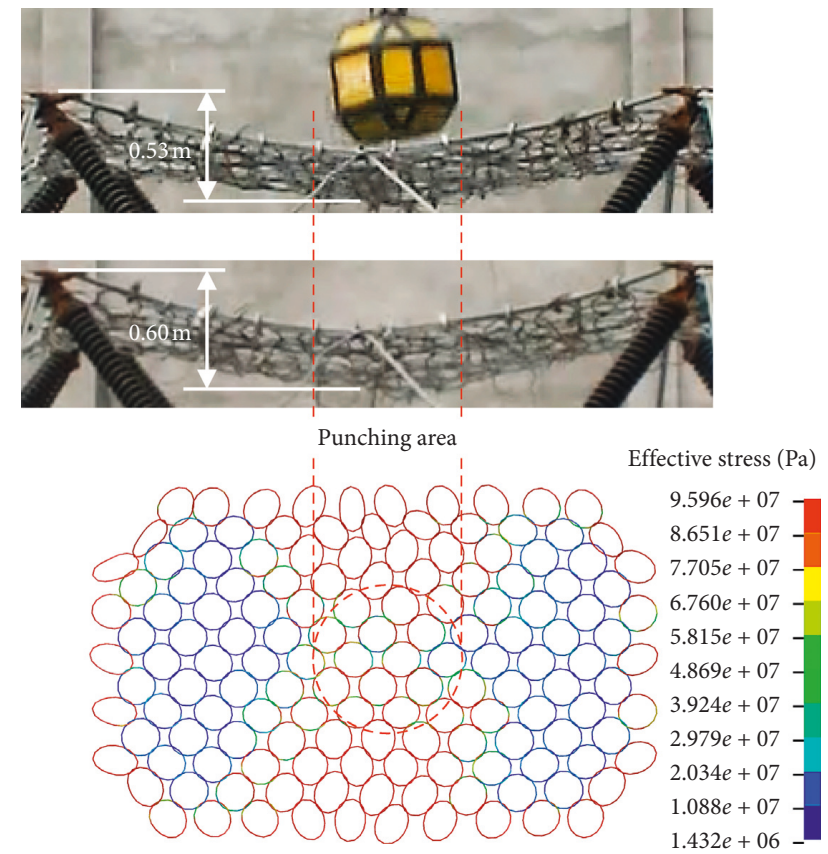

(b)

FIgURE 15: Resilience of the ring nets. (a) Maximum impact. (b) Comparison before and after impact.

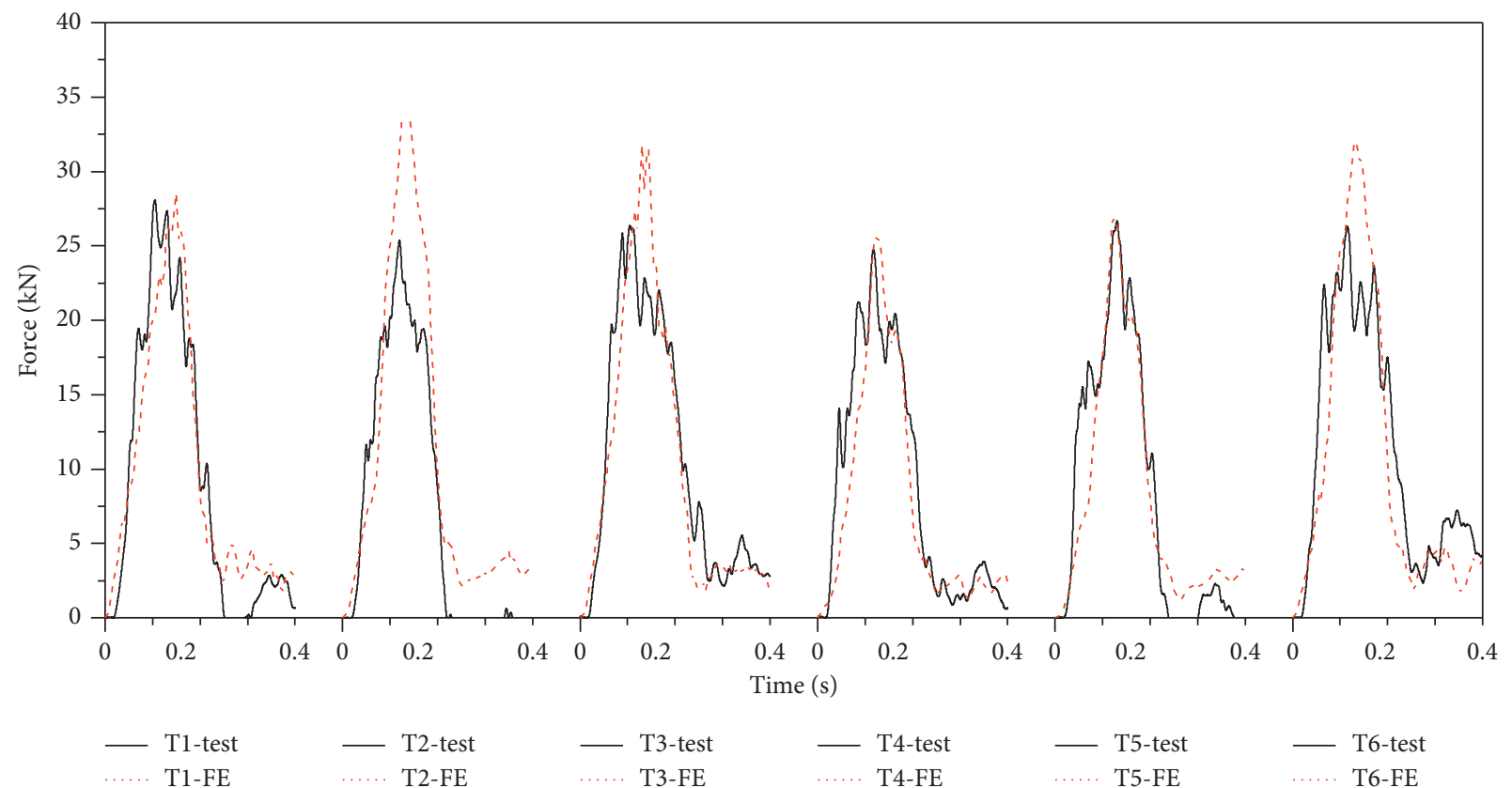

FIgURE 16: Time-history curves of the internal tensile force of the support ropes (see Figure 10(a) for the rope locations). 


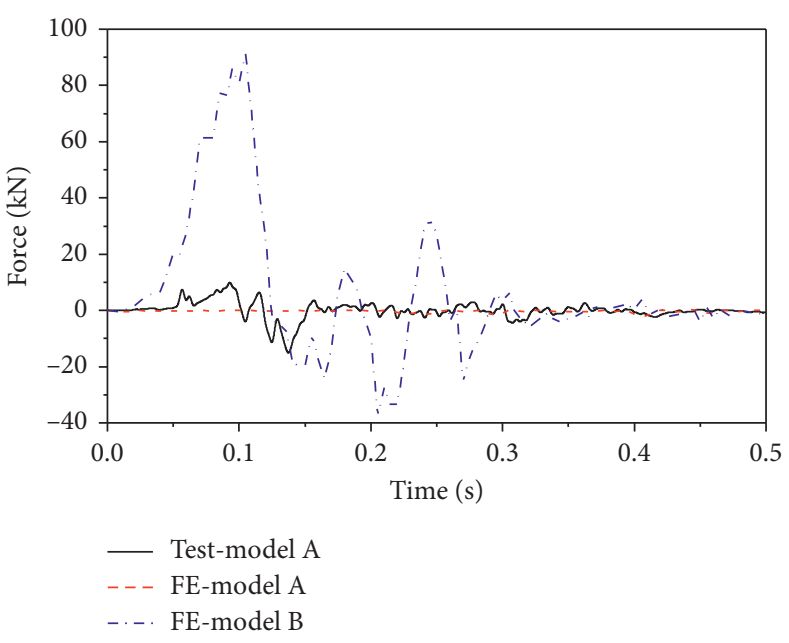

(a)

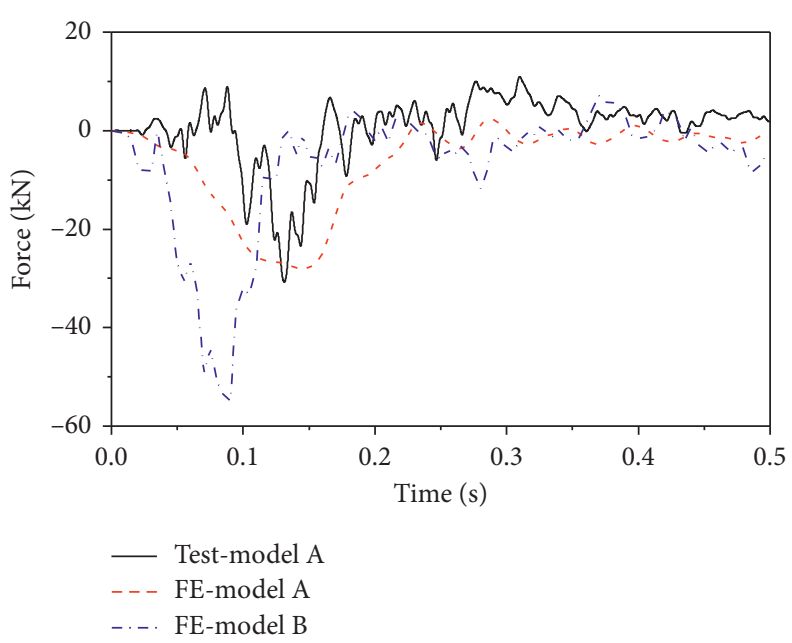

(c)

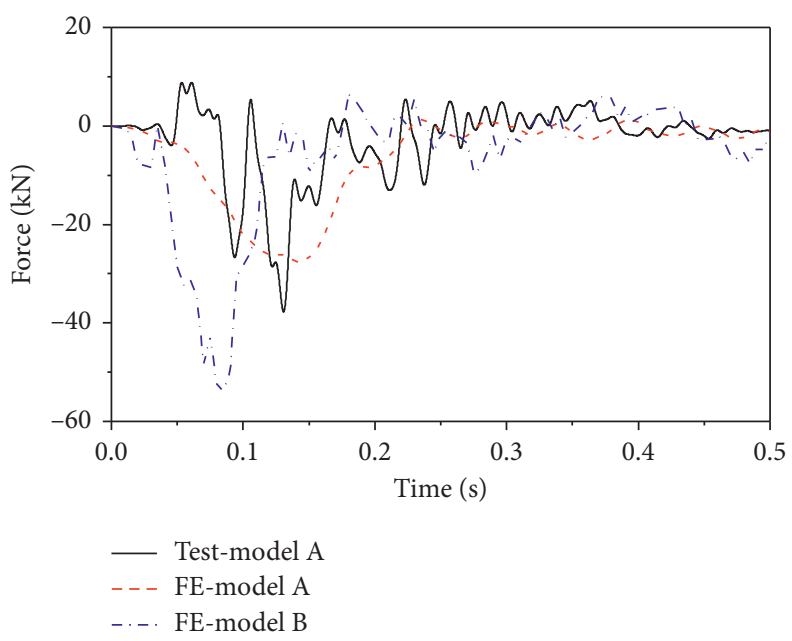

(e)

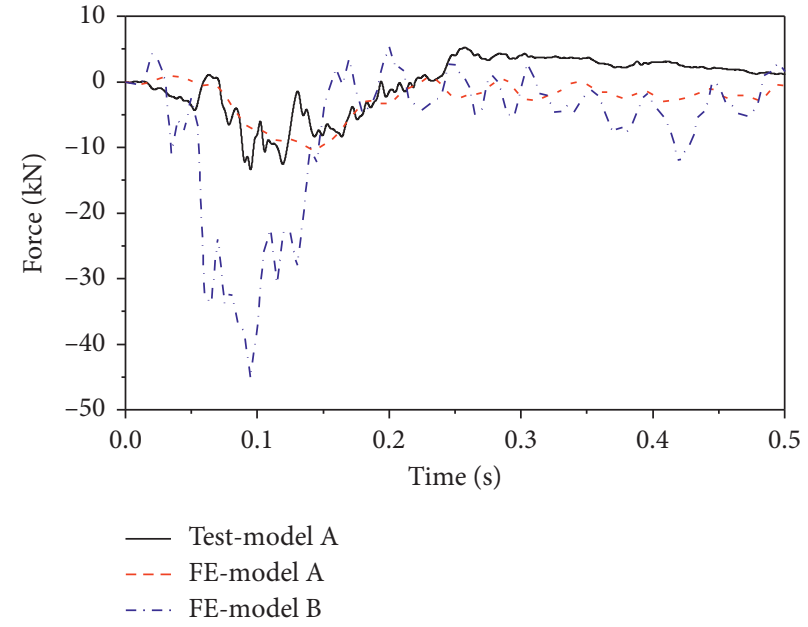

(b)

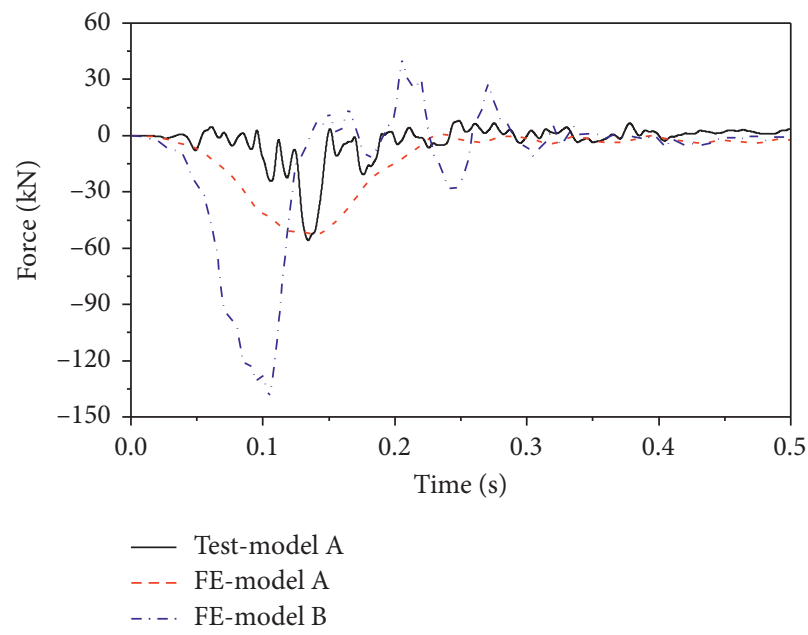

(d)

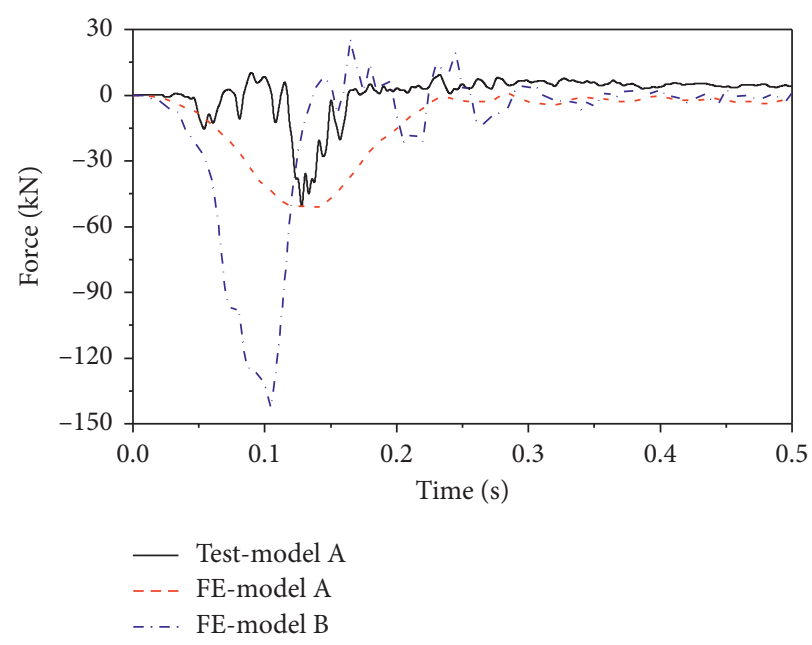

(f)

FIGURE 17: Axial force of spring rods. (a) Measured point S1. (b) Measured point S2. (c) Measured point S3. (d) Measured point S4. (e) Measured point S5. (f) Measured point S6.

oscillation amplitude of the axial force. First, the maximum axial tensile force of model B is almost ten-times greater than that of model A at measured point S1 (Figure 17(a)). The maximum axial compressive force of model $B$ is almost fourtimes greater than that of model A at measured points S2 (Figure 17(b)), S4 (Figure 17(d)), and S6 (Figure 17(f)) and 
is almost two-times greater than that of model $\mathrm{A}$ at measured points S3 (Figure 17(c)) and S5 (Figure 17(e)). Second, while the impact duration of model $\mathrm{A}$ was about $0.23 \mathrm{~s}$, it decreased approximately $67 \%$ to $0.15 \mathrm{~s}$ of model B. Third, the oscillation amplitude of the axial force of model A was much smaller than that of model B.

3.2.4. Conversion and Dissipation of Impact Energy. Figure 18(a) shows the conversion of impact energy throughout the entire impact-rebound process. The energy dissipated by damping increased continuously; this was especially prominent in the first impact-rebound process. While the internal energy increased significantly in the first impact process, it returned to a low level, indicating that the impact energy dissipated by the structure components was negligible. Figure 18(b) shows the dissipation of the impact energy in the first impact-rebound process. Because the additional kinetic energy was transferred from the gravitational potential energy (external work) in the braking distance, the total impact energy was $56.4 \mathrm{~kJ}$. At the end of stage II, when the block was stopped, the potential energy stored in the springs was $28.6 \mathrm{~kJ}$, which is more than half the total kinetic energy of the block. The internal energy of the ring nets was $10.8 \mathrm{~kJ}$, which is about $19 \%$ of the total impact energy. The damping dissipated $14.1 \mathrm{~kJ}$, which is about $25 \%$ of the total impact energy. Other components, such as the support ropes, stored $2.9 \mathrm{~kJ}$, which is about $5 \%$ of the total impact energy. At the end of stage III, when the block was rebounded and detached from the buffer structure, the potential energy stored in the springs was released fully and returned to 0 . The elastic potential energies stored in these components were also released fully; the residual energies were about 0 . The residual kinetic energy of the block was $25.2 \mathrm{~kJ}$; thus, the total energy that was dissipated in the first impact-rebound process was $24.8 \mathrm{~kJ}$. The residual energy stored in the ring net was about $4.5 \mathrm{~kJ}$, which was dissipated by plastic deformation. The energy dissipated by the damping increased to $24.4 \mathrm{~kJ}$, which accounted for $82 \%$ of the total dissipated energy of the block. Consequently, the energy dissipation of the buffer structure is mainly derived from damping. The results further indicate that the buffer structure was impactresilient.

\section{Estimation of the Maximum Impact Force and Braking Distance}

As with the characteristic of a strong nonlinear and large deflection, it is challenging to determine analytical solutions for the maximum force and the braking distance. Considering that the buffer and impact-resilient performance of the structure is mainly contingent upon the springs, springs and spring rods are the key functional components of the buffer structure, so the stiffness of the spring is the most critical parameter. Additionally, the rockfall disaster with the impact energy lower than $2000 \mathrm{~kJ}$ occurs most frequently in engineering, and, as the impact energy increases, the system's resistance requirement will increase, so the strength of spring rod, ring net, and support rope should also increase. If unrecoverable damage happens due to insufficient resistance of structural components, the structure will lose its impactresilient ability. Therefore, in order to ensure that the springs can contribute to the impact-resilient performance of the structure effectively, the structural members should have enough bearing capacity to avoid damage. To ensure that structural damage will not happen in these models and the effect of the change of spring stiffness on the system can be captured, it is necessary to make corresponding changes in the parameters of spring rod, ring net, and support rope. Therefore, numerical simulations of 33 models were conducted; in these models, the impact energy and the spring stiffness ranged from $100 \mathrm{~kJ}$ to $2000 \mathrm{~kJ}$ and from $300 \mathrm{kN} / \mathrm{m}$ to $1500 \mathrm{kN} / \mathrm{m}$, respectively. Table 4 details the parameters of these models. It is worth to note that the parameters of spring stiffness in these models have considered the technical feasibility of manufacturing, and the parameters of other components are determined according to the minimum resistance requirements by trial and error.

Based on the fitting analysis of the simulated maximum impact force (Figure 19(a)) and maximum braking distance (Figure 19(b)), empirical formulas can be obtained for the buffer structure, as seen in the following equations:

$$
\begin{aligned}
& F=\alpha \cdot E_{\mathrm{k}}^{0.62} \cdot k^{0.16}, \\
& d=\beta \cdot E_{k}^{0.17} \cdot k^{-0.13},
\end{aligned}
$$

where $\alpha$ and $\beta$ are the correction factors and the empirical values are 4.5 and 1.8 , respectively.

Data from the previous impact test with an impact energy of $50 \mathrm{~kJ}$ are used to verify this approach. By applying equation (3), the estimated impact force is $117.9 \mathrm{kN}$, which fits well with the measured maximum impact force $(107.8 \mathrm{kN})$. By applying equation (4), the estimated braking distance is $1.67 \mathrm{~m}$, which also fits well with the measured braking distance $(1.55 \mathrm{~m})$. Thus, preliminarily, this simple approach can be proven to be feasible. By applying this simple approach, the designed impact force and braking distance of rockfalls can be easily estimated using the basic parameters of possible falling rocks and the selected springs. This is very helpful for selecting the parameters of the buffer structure.

\section{Conclusions}

This paper proposed an impact-resilient flexible buffer structure for rockfall protection based on the concept of the impact-resilient structure that was discussed first. It then discussed the design of a full-scale model, and two impact tests, with an impact energy of $25 \mathrm{~kJ}$ and $50 \mathrm{~kJ}$, respectively, that were conducted in succession to study the impactresilient characteristic of the structure combined with numerical simulation. Finally, it discussed the parametric numerical simulations of 33 models that were conducted to study the influence of spring stiffness on the dynamic 


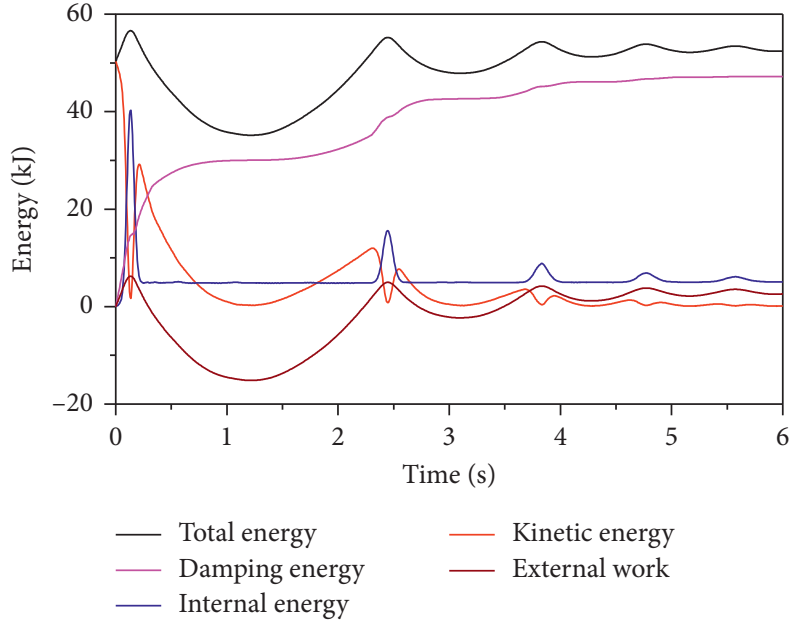

(a)

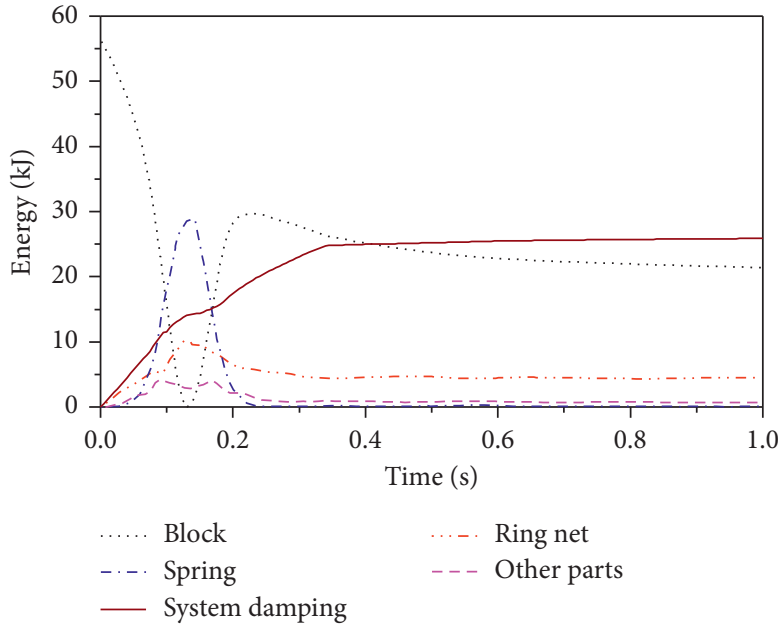

(b)

Figure 18: Conversion and dissipation of the impact energy. (a) Conversion of impact energy. (b) Dissipation of impact energy.

TABLE 4: Parameters of the simulation models.

\begin{tabular}{|c|c|c|c|c|c|}
\hline \multirow{2}{*}{ No. } & \multirow{2}{*}{ Impact energy $(\mathrm{kJ})$} & \multicolumn{4}{|c|}{ Component parameters } \\
\hline & & Spring rods (upper + lower) & Spring stiffness $(\mathrm{kN} / \mathrm{m})$ & Ring nets & Support ropes \\
\hline 1 & 100 & $\Phi 48 \times 9+\Phi 68 \times 8.5$ & $300-1500$ & $\mathrm{R} 7 / 3 / 300$ & $2 \Phi 18$ \\
\hline 2 & 200 & Ф60x10 + Ф89x9 & $400-1500$ & $\mathrm{R} 9 / 3 / 300$ & $2 \Phi 18$ \\
\hline 3 & 500 & $\Phi 89 \times 10+\Phi 114 x 9$ & $700-1500$ & $\mathrm{R} 12 / 3 / 300$ & $2 \Phi 18$ \\
\hline 4 & 1500 & $\Phi 159 \times 12+\Phi 180 \times 10$ & $800-1500$ & $\mathrm{R} 19 / 3 / 300$ & $2 \Phi 20$ \\
\hline 5 & 2000 & $\Phi 168 \times 16+\Phi 194 \times 10$ & $1000-1500$ & $\mathrm{R} 19 / 3 / 300$ & $2 \Phi 22$ \\
\hline
\end{tabular}

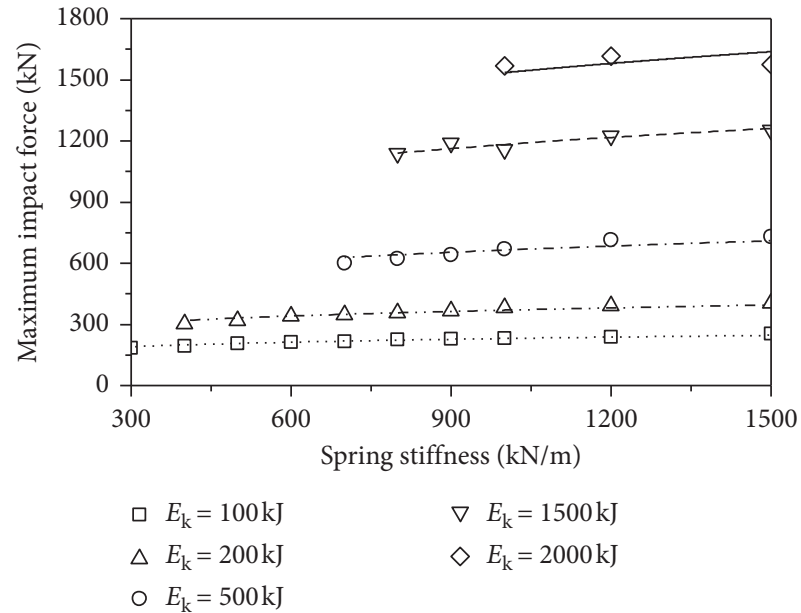

(a)

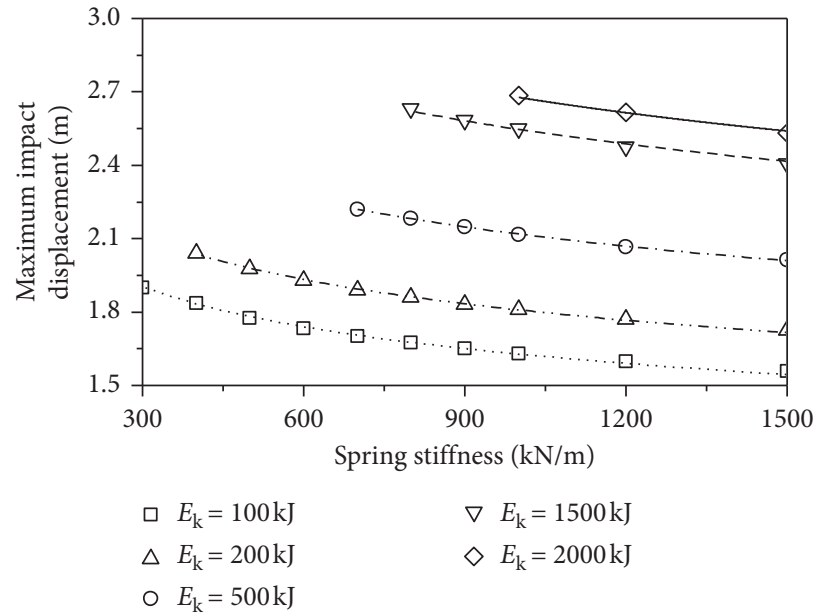

(b)

FIgURE 19: The simulation results and fitting curves. (a) The maximum impact force $F$. (b) The maximum braking distance $d$.

responses of the structure. In summary, the following conclusions can be drawn from this paper:

(a) The proposed flexible buffer structure is mainly composed of springs, ring nets, spring rods, and support ropes. The buffer structure can be placed on the top of an RC rock shed or a steel rock shed to replace the traditional cushion layer. (b) The energy dissipation of the buffer structure is mainly derived from damping. The buffer structure will almost be restored to its original state after impact, indicating that the buffer structure is impact-resilient.

(c) The proposed spring-piston element is useful for modelling the spring rod of the flexible buffer structure. 
(d) Simple approaches for estimating the impact force and braking distance of the flexible buffer structure were proposed and verified using measured data obtained from the impact test.

It is worth to note that, in practice, if the flexible buffer structure is designed and installed at a slanted angle, the rockfalls will be rebounded out of the protected area during the first rebound process. In other words, the flexible buffer structure has a self-cleaning feature. If the buffer structures are installed in the wild environment, without buildings and facilities nearby, only the roadway or railway areas are the protected targets, and the goal of the protection is achieved when the falling rocks do not impact these areas. Moreover, to prevent rocks falling from both ends of the shed, interception structures, such as fences [39], should also be installed at both ends of the structure. Otherwise, to protect the nearby buildings and facilities from the impact of falling rocks that are rebounded out by the buffer structure, passive rockfall barrier systems [21-23, 29, 30] or hybrid protection systems [40] can be installed to intercept the falling rock on the ground or guide them to a place where it is convenient for cleaning, achieving a comprehensive protection goal.

Finally, although the mass weighted damping factor of the block assumed in this paper seems to be reasonable, an in-depth study is warranted, especially research that investigates how time-varying structural stiffness influences the damping factor.

\section{Data Availability}

The data used to support the findings of this study are available from the corresponding author upon request.

\section{Conflicts of Interest}

The authors declare that they have no conflicts of interest.

\section{Acknowledgments}

The authors are grateful to the National Key Research and Development Program of China (grant no. 2018YFC 1505405), the National Natural Science Foundation of China (grant no. 51678504), the Department of Science and Technology of Sichuan Province (grant no. 2018JY0029), the Science and Technology Research and Development Program of China Railway Corporation (grant no. 2018KY10), the Fundamental Research Funds for the Central Universities (grant no. 2682019ZT03), and the Shock and Vibration of Engineering Material and Structure Key Laboratory of Sichuan Province (grant no. 18kfgk07).

\section{References}

[1] T. S. Ho, H. Masuya, and N. Takashita, "Experimental study concerning impact characteristics by collision of weight on sand cushion over steel beam," International Journal of Geomate, vol. 4, pp. 471-476, 2013.

[2] S. H. Hsu, K. Maegawa, and L. H. Chen, "Experimental study on the EPS-based shock absorber for rock-shed," International Journal of Geomate, vol. 11, pp. 2534-2540, 2016.
[3] S. H. Hsu, K. Maegawa, and A. Hama, "Full-scale testing and modeling of rock-shed shock absorbers under impact loads," International Journal of Protective Structures, vol. 9, no. 2, pp. 157-173, 2018.

[4] S. Kawahara and T. Muro, "Effects of dry density and thickness of sandy soil on impact response due to rockfall," Journal of Terramechanics, vol. 43, no. 3, pp. 329-340, 2006.

[5] N. Kishi, H. Konno, K. Ikeda, and K. G. Matsuoka, "Prototype impact tests on ultimate impact resistance of PC rock-sheds," International Journal of Impact Engineering, vol. 27, no. 9, pp. 969-985, 2002.

[6] B. Pichler, C. Hellmich, and H. A. Mang, "Impact of rocks onto gravel design and evaluation of experiments," International Journal of Impact Engineering, vol. 31, no. 5, pp. 559-578, 2005.

[7] K. Schellenberg, A. Volkwein, A. Roth, and T. Vogel, "Rockfall-falling weight tests on galleries with special cushion layers," in Proceedings of the 3rd International Conference on Protection of Structures Against Hazards, pp. 251-258, Venice, Italy, September 2006.

[8] A. Volkwein, K. Schellenberg, V. Labiouse et al., "Rockfall characterisation and structural protection-a review," Natural Hazards and Earth System Sciences, vol. 11, no. 9, pp. 2617-2651, 2011.

[9] P. Zhao, L. Xie, L. Li, Q. Liu, and S. Yuan, "Large-scale rockfall impact experiments on a RC rock-shed with a newly proposed cushion layer composed of sand and EPE," Engineering Structures, vol. 175, pp. 386-398, 2018.

[10] F. Delhomme, M. Mommessin, J. P. Mougin, and P. Perrotin, "Behavior of a structurally dissipating rock-shed: experimental analysis and study of punching effects," International Journal of Solids and Structures, vol. 42, no. 14, pp. 4204-4219, 2005.

[11] F. Delhomme, M. Mommessin, J.-P. Mougin, and P. Perrotin, "Damage mechanisms of a reinforced concrete rock-shed slab impacted by blocks," Journal of Structural Engineering, vol. 133, no. 10, pp. 1426-1433, 2007.

[12] Z. L. Wang, Y. C. Li, and J. G. Wang, "Numerical analysis of attenuation effect of EPS geofoam on stress-waves in civil defense engineering," Geotextiles and Geomembranes, vol. 24, no. 5, pp. 265-273, 2006.

[13] S. Zarnani and R. J. Bathurst, "Numerical parametric study of expanded polystyrene (EPS) geofoam seismic buffers," $\mathrm{Ca}$ nadian Geotechnical Journal, vol. 46, no. 3, pp. 318-338, 2009.

[14] J. Sun, Z. Chu, Y. Liu, W. Luo, and M. Wang, "Performance of used tire cushion layer under rockfall impact," Shock and Vibration, vol. 2016, Article ID 8760592, 10 pages, 2016, in Chinese.

[15] A. Effeindzourou, K. Thoeni, A. Giacomini, and C. Wendeler, "Efficient discrete modelling of composite structures for rockfall protection," Computers and Geotechnics, vol. 87, pp. 99-114, 2017.

[16] J. P. Mougin, P. Perrotin, M. Mommessin, J. Tonnelo, and A. Agbossou, "Rock fall impact on reinforced concrete slab: an experimental approach," International Journal of Impact Engineering, vol. 31, no. 2, pp. 169-183, 2005.

[17] L. Castanon-Jano, E. Blanco-Fernandez, D. Castro-Fresno, and F. Ballester-Muñoz, "Energy dissipating devices in falling rock protection barriers," Rock Mechanics and Rock Engineering, vol. 50, no. 3, pp. 603-619, 2017.

[18] S. Q. Shi, M. Wang, X. Q. Peng, and Y. K. Yang, "A new-type flexible rock-shed under the impact of rock block: initial 
experimental insights," Natural Hazards and Earth System Sciences, vol. 13, no. 12, pp. 3329-3338, 2013.

[19] L. Cui, M. Wang, and T. Yu, "Dynamic finite element analysis of a new type flexible rock shed under the impact of rock block and improving the design," Shock and Vibration, vol. 2018, Article ID 1936560, 16 pages, 2018.

[20] J. S. H. Kwan, S. L. Chan, J. C. Y. Cheuk, and R. C. H. Koo, "A case study on an open hillside landslide impacting on a flexible rockfall barrier at Jordan Valley, Hong Kong," Landslides, vol. 11, no. 6, pp. 1037-1050, 2014.

[21] Z. X. Yu, Y. K. Qiao, L. Zhao, H. Xu, S. C. Zhao, and Y. P. Liu, "A simple analytical method for evaluation of flexible rockfall barrier part 1: working mechanism and analytical solution," Advanced Steel Construction, vol. 14, no. 2, pp. 115-141, 2018.

[22] Z. X. Yu, Y. K. Qiao, L. Zhao, H. Xu, S. C. Zhao, and Y. P. Liu, "A simple analytical method for evaluation of flexible rockfall barrier part 2: application and full-scale test," Advanced Steel Construction, vol. 14, no. 2, pp. 142-165, 2018.

[23] Z. X. Yu, L. Zhao, Y. P. Liu, S. C. Zhao, H. Xu, and S. L. Chan, "Studies on flexible rockfall barriers for failure modes, mechanisms and design strategies: a case study of Western China," Landslides, vol. 16, no. 2, pp. 347-362, 2018.

[24] C. Folke, "Resilience: the emergence of a perspective for social-ecological systems analyses," Global Environmental Change, vol. 16, no. 3, pp. 253-267, 2006.

[25] T. McDaniels, S. Chang, D. Cole, J. Mikawoz, and H. Longstaff, "Fostering resilience to extreme events within infrastructure systems: characterizing decision contexts for mitigation and adaptation," Global Environmental Change, vol. 18, no. 2, pp. 310-318, 2008.

[26] C. S. Holling, "Engineering resilience versus ecological resilience," in Engineering within Ecological Constraints, P. Schulze, Ed., pp. 31-44, National Academies Press, Washington, DC, USA, 1996.

[27] L. Q. Zhang, Z. F. Yang, J. W. Zhu, and Y. Liu, "Operational principle of spring buffer and its application in flexible rockfall prevention system," Journal of Geological Hazards and Environment Preservation, vol. 18, pp. 108-112, 2007, in Chinese.

[28] Z. G. Lv, Study on Impact Resistance of Spring Lattice Debris Flow Dam, Lanzhou University of Technology, Lanzhou, China, 2014, in Chinese.

[29] C. Gentilini, L. Govoni, S. de Miranda, G. Gottardi, and F. Ubertini, "Three-dimensional numerical modelling of falling rock protection barriers," Computers and Geotechnics, vol. 44, pp. 58-72, 2012.

[30] C. Gentilini, G. Gottardi, L. Govoni, A. Mentani, and F. Ubertini, "Design of falling rock protection barriers using numerical models," Engineering Structures, vol. 50, pp. 96106, 2013.

[31] S. C. Zhao, Z. X. Yu, L. Zhao, X. Qi, and T. Wei, "Damage mechanism of rockfall barriers under strong impact loading," Engineering Mechanics, vol. 33, pp. 24-34, 2016, in Chinese.

[32] EOTA, Guidelines for European Technical Approval of Falling Rock Protection Kits-ETAG 027, EOTA, Brussels, Belgium, 2013.

[33] S. C. Zhao, Z. X. Yu, T. Wei, and X. Qi, “Test study of force mechanism and numerical calculation of safety netting system," China Civil Engineering Journal, vol. 46, pp. 122-128, 2013, in Chinese.

[34] H. Xu, C. Gentilini, Z. Yu, X. Qi, and S. Zhao, "An energy allocation based design approach for flexible rockfall protection barriers," Engineering Structures, vol. 173, pp. 831-852, 2018 .
[35] X. Qi, Z. X. Yu, L. Zhao, H. Xu, and S. C. Zhao, "A new numerical modelling approach for flexible rock fall protection barriers based on failure mode," Advanced Steel Construction, vol. 14, pp. 479-495, 2018.

[36] Z. X. Yu, S. W. Yan, H. Xu et al., "Mechanical behavior of piston rod point-supported flexible buffer system," China Civil Engineering Journal, vol. 51, no. 11, pp. 61-112, 2018, in Chinese.

[37] J. O. Hallquist, LS-DYNA Theory Manual, Livermore Software Technology Corporation, Livermore, CA, USA, 2006.

[38] LSTC, LS-DYNA Keyword User's Manual Volume I, LSTC (Livermore Software Technology Corporation), Livermore, CA, USA, 2013.

[39] P. V. Tran, K. Maegawa, and S. Fukada, "Prototype of a wirerope rockfall protective fence developed with threedimensional numerical modeling," Computers and Geotechnics, vol. 54, pp. 84-93, 2013.

[40] S. Dhakal, N. P. Bhandary, R. Yatabe, and N. Kinoshita, "Numerical and analytical investigation towards performance enhancement of a newly developed rockfall protective cablenet structure," Natural Hazards and Earth System Sciences, vol. 12, no. 4, pp. 1135-1149, 2012. 


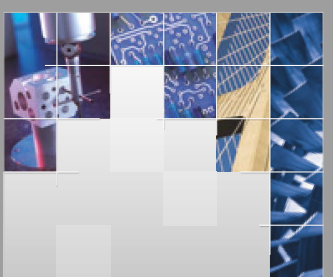

\section{Enfincering}
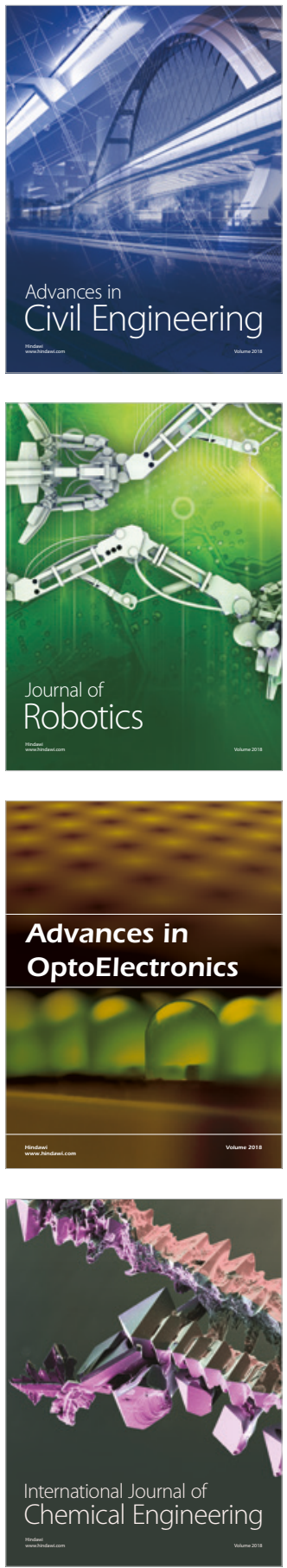

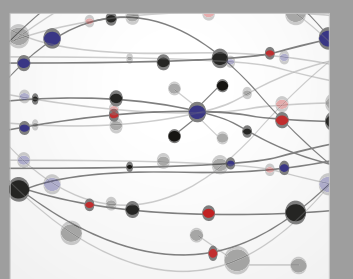

\section{Rotating \\ Machinery}

The Scientific World Journal

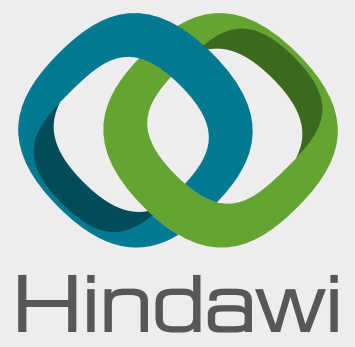

Submit your manuscripts at

www.hindawi.com
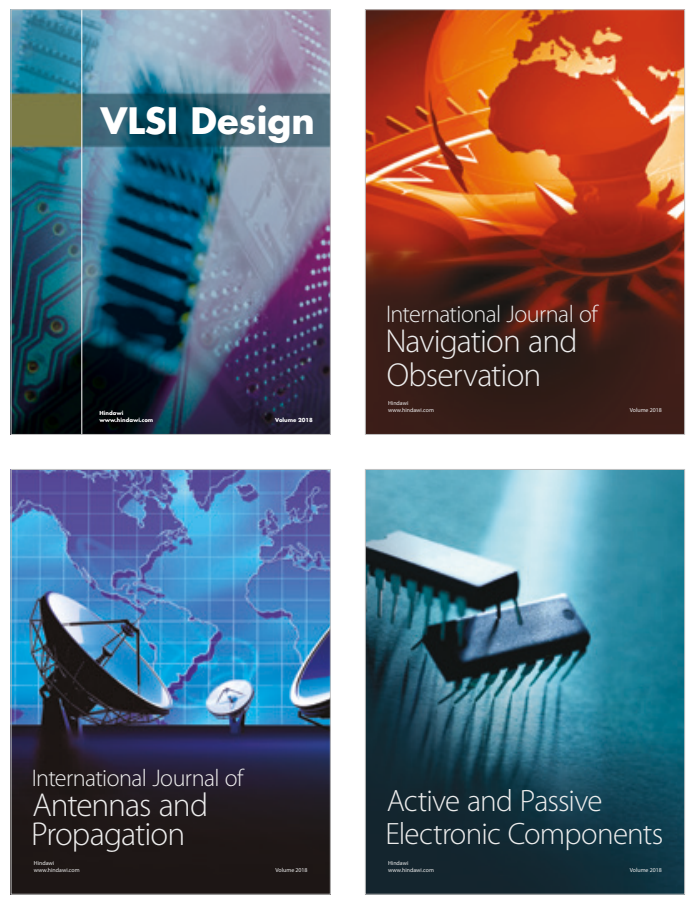
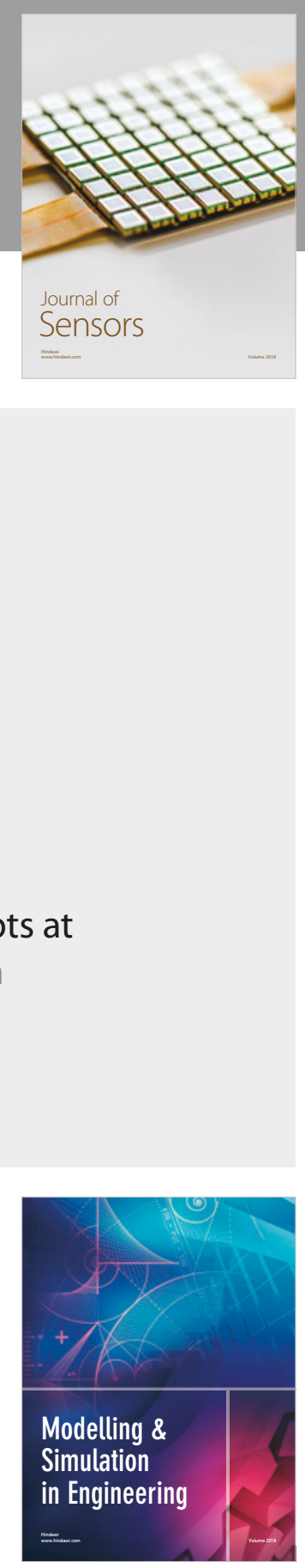

\section{Advances \\ Multimedia}
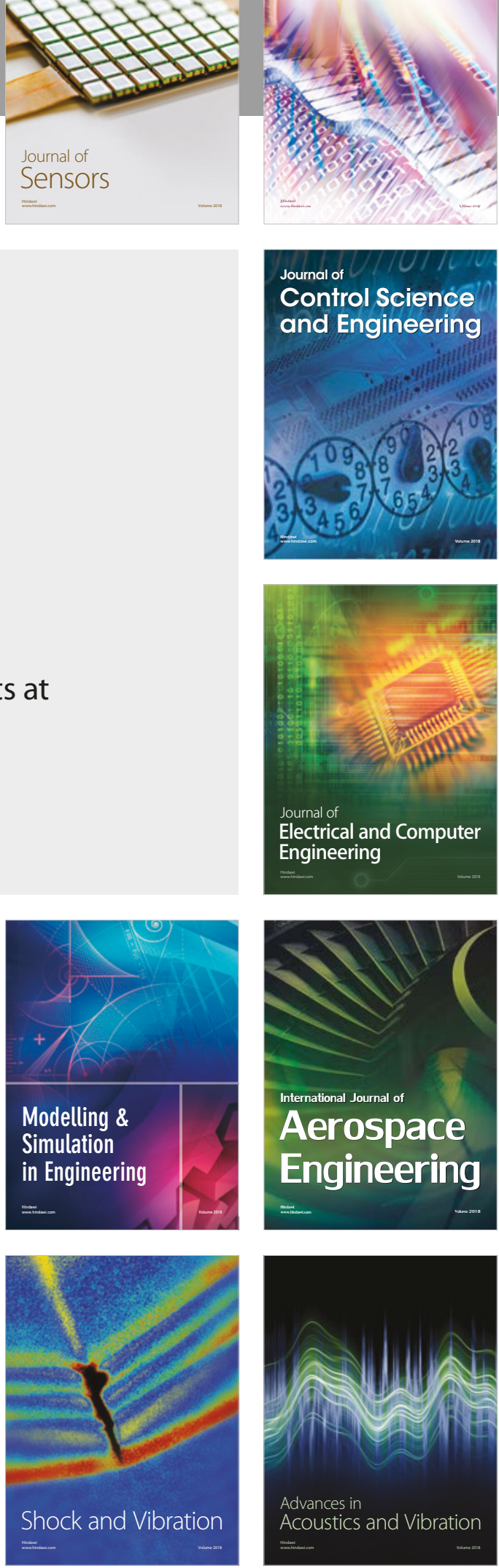